\title{
Tectonic stress pattern in the Chinese Mainland from the inversion of focal mechanism data
}

\author{
Ju WeI ${ }^{1,2, *} \mathbb{D}$, Sun WeIfeng ${ }^{1}$ and MA XIAOJING ${ }^{3}$ \\ ${ }^{1}$ School of Resources and Geosciences, China University of Mining and Technology, Xuzhou 221116, China. \\ ${ }^{2}$ Key Laboratory of Coalbed Methane Resources and Reservoir Formation Process, Ministry of Education, \\ China University of Mining and Technology, Xuzhou 221008, China. \\ ${ }^{3}$ College of Resources, Hebei GEO University, Shijiazhuang 050031, China. \\ *Corresponding author. e-mail: wju@cumt.edu.cn
}

The tectonic stress pattern in the Chinese Mainland and kinematic models have been subjected to much debate. In the past several decades, several tectonic stress maps have been figured out; however, they generally suffer a poor time control. In the present study, 421 focal mechanism data up to January 2010 were compiled from the Global/Harvard CMT catalogue, and 396 of them were grouped into 23 distinct regions in function of geographic proximity. Reduced stress tensors were obtained from formal stress inversion for each region. The results indicated that, in the Chinese Mainland, the directions of maximum principal stress were $\sim \mathrm{NE}-\mathrm{SW}$-trending in the northeastern region, $\sim \mathrm{NEE}-\mathrm{SWW}$-trending in the North China region, $\sim \mathrm{N}-\mathrm{S}$-trending in western Xinjiang, southern Tibet and the southern Yunnan region, $\sim$ NNE-SSW-trending in the northern Tibet and Qinghai region, $\sim$ NW-SE-trending in Gansu region, and $\sim \mathrm{E}-\mathrm{W}$-trending in the western Sichuan region. The average tectonic stress regime was strikeslip faulting (SS) in the eastern Chinese Mainland and northern Tibet region, normal faulting (NF) in the southern Tibet, western Xinjiang and Yunnan region, and thrust faulting (TF) in most regions of Xinjiang, Qinghai and Gansu. The results of the present study combined with GPS velocities in the Chinese Mainland supported and could provide new insights into previous tectonic models (e.g., the extrusion model). From the perspective of tectonics, the mutual actions among the Eurasian plate, Pacific plate and Indian plate caused the present-day tectonic stress field in the Chinese Mainland.

\section{Introduction}

Tectonic stress is one of the fundamental datasets in Earth Sciences comparable with topography, gravity, heat flow and others (Sperner et al. 2003). Thus, an investigation into the crustal tectonic stresses is a key point in earth geotectonic studies (Hou et al. 2006; Lunina and Gladkov 2007; Ju et al. 2013a, 2016; Baruah et al. 2013, 2016; NaimiGhassabian et al. 2015). Furthermore, knowledge of the tectonic stress field can be used in the hydrocarbon industry to foresee stability problems and tectonic fractures (Ju et al. 2013b, 2014, 2015; Ju and Sun 2016), and to optimize reservoir management through tectonic modelling (Sperner et al.
2003). In general, the focal mechanism data and their analysis allow and facilitate a revisiting of tectonic interpretations of the present-day stress field (Delvaux and Barth 2010; Naimi-Ghassabian et al. 2015). The stress patterns obtained from formal stress inversion of focal mechanism solutions can reveal many things in the stress field that were not captured by large-scale numerical models of previous studies.

China contains some of the most complex geology in the world, ranging from a number of ancient Archean cratons to active tectonic belts, and offshore marine basins (Tapponnier and Molnar 1977; Yin 2010; figure 1). During the past several decades, the number of focal mechanisms available

Keywords. Tectonic stress pattern; focal mechanism; Chinese Mainland; stress regime; driving force. 
for Chinese Mainland increased considerably due to a longer observation time, improvement of the seismic network and more detailed calculation procedures; therefore, it is possible to image the tectonic stress for Chinese Mainland.

In this study, initially, available well constrained focal mechanism data in the Chinese Mainland up to January 2010 (421 events) from the Global/ Harvard CMT catalogue were compiled; after that, 396 of them were grouped into 23 distinct regions (boxes) in function of geographic proximity. Formal inversions were performed to determine the present-day stress field and discuss the tectonic stress regime and driving forces.

\section{Data compilation and zonation}

The Global CMT Project - formerly Harvard CMT (Dziewonski et al. 1987) - routinely determines focal mechanisms by moment tensor inversion of both long period body- and surface-waves. In this study, altogether 421 focal mechanisms $(\mathrm{Mw} \geq 5.0)$ were compiled (listed in the Appendix) to perform stress inversions and discuss the results in terms of the Chinese Mainland tectonics. In the compiled database, the direction of horizontal stress $\left(\mathrm{S}_{\mathrm{H} \max }\right.$ and $\left.\mathrm{S}_{\mathrm{hmin}}\right)$ computed according to Lund and Townend (2007) and stress regime (NF: normal faulting, SS: strike-slip faulting, TF: thrust faulting, NS: intermediate between NF and SS, TS: intermediate between SS and TF, UF: unknown or oblique faulting) were given for each individual focal mechanism.

In the Chinese Mainland, the focal mechanism data vary in terms of stress regime and stress orientation; therefore, they cannot be inverted altogether. In the present study, the region was divided into sub-areas to study regional changes in stress orientation and stress regime (Barth et al. 2007; Delvaux and Barth 2010). In view of this, the

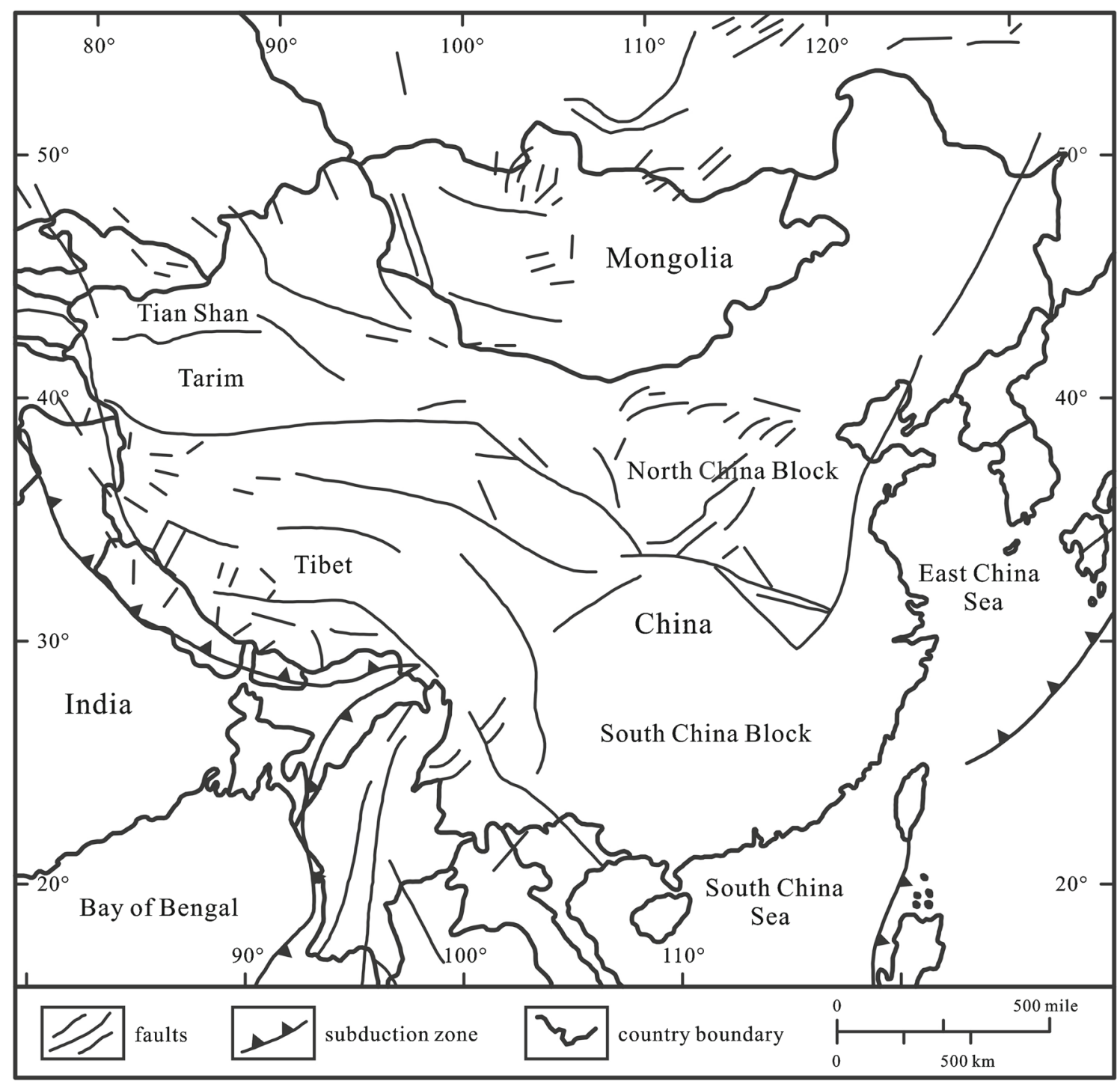

Figure 1. Tectonic map of the Chinese Mainland and adjacent regions (after Tapponnier et al. 1986 and Zhang et al. 2003). 
zonation of the Global Seismic Hazard Assessment Program (GSHAP) was applied as a starting point, which took into account the recent and historic seismicity and hence defined areas with a common seismic risk (Zhang 1993; Giardini 1999; Zhang et al. 1999; Delvaux and Barth 2010). In addition, the China National Seismic Zonation Map (CNSZM; Gao 2003) also contributed to the subdivision.

In this study, 396 of the total 421 data were assembled into 23 boxes (listed in Appendix) on the basis of their geographical proximity and geological setting.

\section{Tectonic stress inversion}

The determination of present-day tectonic stress and stress regime based on the inversion of earthquake focal mechanisms has been studied by several authors (e.g., Angelier 1984, 1989; Gephart and Forsyth 1984; Delvaux et al. 1995). The inversion is mainly based on the assumption that (a) the stress field is uniform and invariant in space and time, and (b) slip on a plane occurs in the direction of the maximum resolved shear stress (Bott 1959; Etchecopar et al. 1981; Delvaux and Barth 2010; Baruah et al. 2013; Naimi-Ghassabian et al. 2015).

In general, the state of tectonic stress at any point of the Earth can be defined by six independent parameters, e.g., three angles specifying the orientation of the stress tensor's eigenvectors and three corresponding eigenvalues (Lund and
Townend 2007). However, stress tensor estimation using earthquake focal mechanism does not retrieve all the six independent components. The four parameters, the orientation of the three orthogonal principal stress axes $\sigma_{1}, \sigma_{2}$ and $\sigma_{3}$ (where $\sigma_{1} \geq \sigma_{2} \geq \sigma_{3}$ ) and the stress ratio $R$, of the reduced stress tensor that models best the state of stress of a given region can be determined. The stress ratio $R$, which shows the magnitude of $\sigma_{2}$ relative to the magnitudes of $\sigma_{1}$ and $\sigma_{3}$, can be expressed as follows (equation 1; Etchecopar et al. 1981; Gephart and Forsyth 1984; Delvaux and Sperner 2003; Cortes and Angelier 2005):

$$
R=\frac{\sigma_{2}-\sigma_{3}}{\sigma_{1}-\sigma_{3}} .
$$

The four parameters estimated from focal mechanism inversions are sufficient to estimate the direction of the maximum horizontal stress axis and stress regimes based on the guidelines and terminology first presented by Zoback (1992) and the formula of Lund and Townend (2007).

In the present study, the Win-TENSOR program (the Windows version of the TENSOR program; version 5.8; Delvaux and Sperner 2003; Delvaux and Barth 2010) was used for tectonic stress inversion. Initially, the 'Right Dihedron Method (RDM)' was used for determination of the range of possible $\sigma_{1}$ and $\sigma_{3}$ orientations. The results acted as starting points for the iterative 'Rotational Optimization Method (ROM)' (Delvaux and Sperner 2003), which

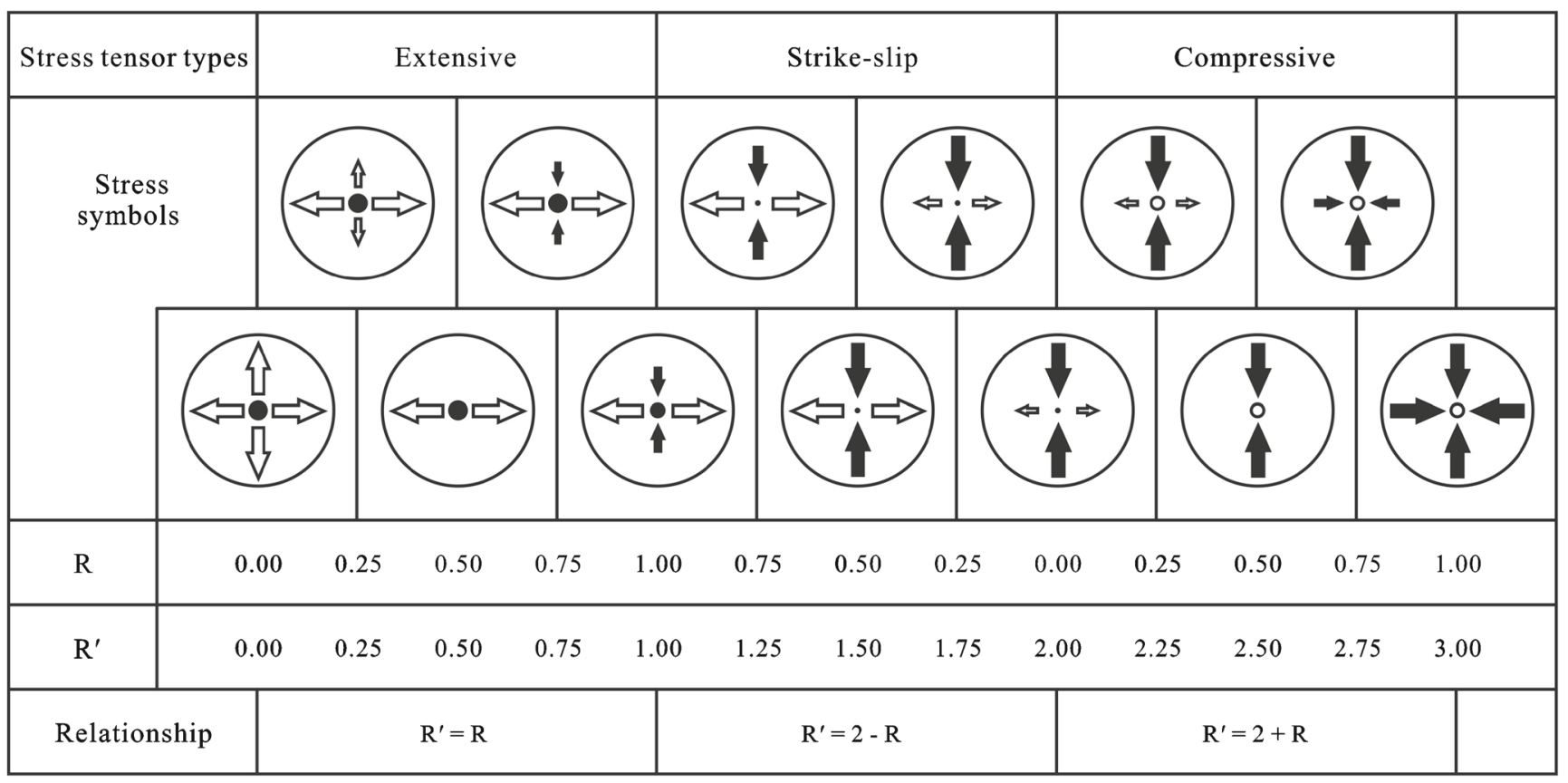

Figure 2. Types of stress regimes and their representations (after Delvaux et al. 1997). Arrows indicate the azimuth of horizontal stress axes, with their length according to the relative stress magnitude. While outward arrows indicate extensive deviatoric stress axes, black inward arrows indicate compressive deviatoric stress axes. Vertical stress axes are symbolized by a solid circle for extensive regimes ( $\sigma_{1}$ vertical), a dot for strike-slip regimes ( $\sigma_{2}$ vertical) and an empty circle for compressive regimes $\left(\sigma_{3}\right.$ vertical). 
is based on the testing of a great number of different stress tensors with the aim of minimizing a misfit function (misfit function F5 in the WinTENSOR program; version 5.8).

In general, the minimization function has the following form (equation 2):

$$
F_{j}=\frac{\sum\left(f_{j}(i) \times w(i)\right)}{n \times \sum w(i)},
$$

where $w(i)$ is the weight of the individual data and $f_{j}(i)$ is the function that has to be minimized.

The angle between the calculated shear stress $\tau$ and the slip vector $d$ is the fit angle $\alpha$. Thus, the corresponding misfit function to be minimized for each earthquake $i$ is the misfit angle $\alpha$ (equation 3):

$$
f(i)=\alpha(i) .
$$

In addition, it is also common to use a least-square function for the minimization (equation 4; Angelier 1984, 1989; Delvaux and Barth 2010), which implies a Gaussian-type distribution of individual misfits.

$$
f(i)=\sin ^{2}\left(\frac{\alpha(i)}{2}\right) .
$$

Initially, both the nodal planes for each focal mechanism are inverted to a stress tensor, then the plane that is best explained by the stress tensor (namely smaller value of function F5 in the program) is selected and viewed as the actual focal plane. After the separation, the following inversion then includes only the focal planes that are best fitted by a uniform stress field (Gephart and Forsyth 1984; Delvaux and Barth 2010; Naimi-Ghassabian et al. 2015).

The stress index $R^{\prime}$ is defined from a combination of the stress ratio $R$ and the nature of the most vertical principal stress axes (Delvaux et al. 1997; Delvaux and Sperner 2003). Based on the stress index $R^{\prime}$, we can define all types of stress regime systematically. It is ranging from 0 to 3 as follows (equation 5 and figure 2; Delvaux et al. 1997; Delvaux and Sperner 2003; Zhang and Wang 2004):

$$
\begin{aligned}
R^{\prime}= & R, \text { when } \sigma_{1} \text { is vertical } \\
& (\text { extensional stress regime }) ; \\
R^{\prime}= & 2-R, \text { when } \sigma_{2} \text { is vertical } \\
& (\text { strike-slip stress regime) } \\
R^{\prime}= & 2+R, \text { when } \sigma_{3} \text { is vertical } \\
& (\text { compressive stress regime }) .
\end{aligned}
$$

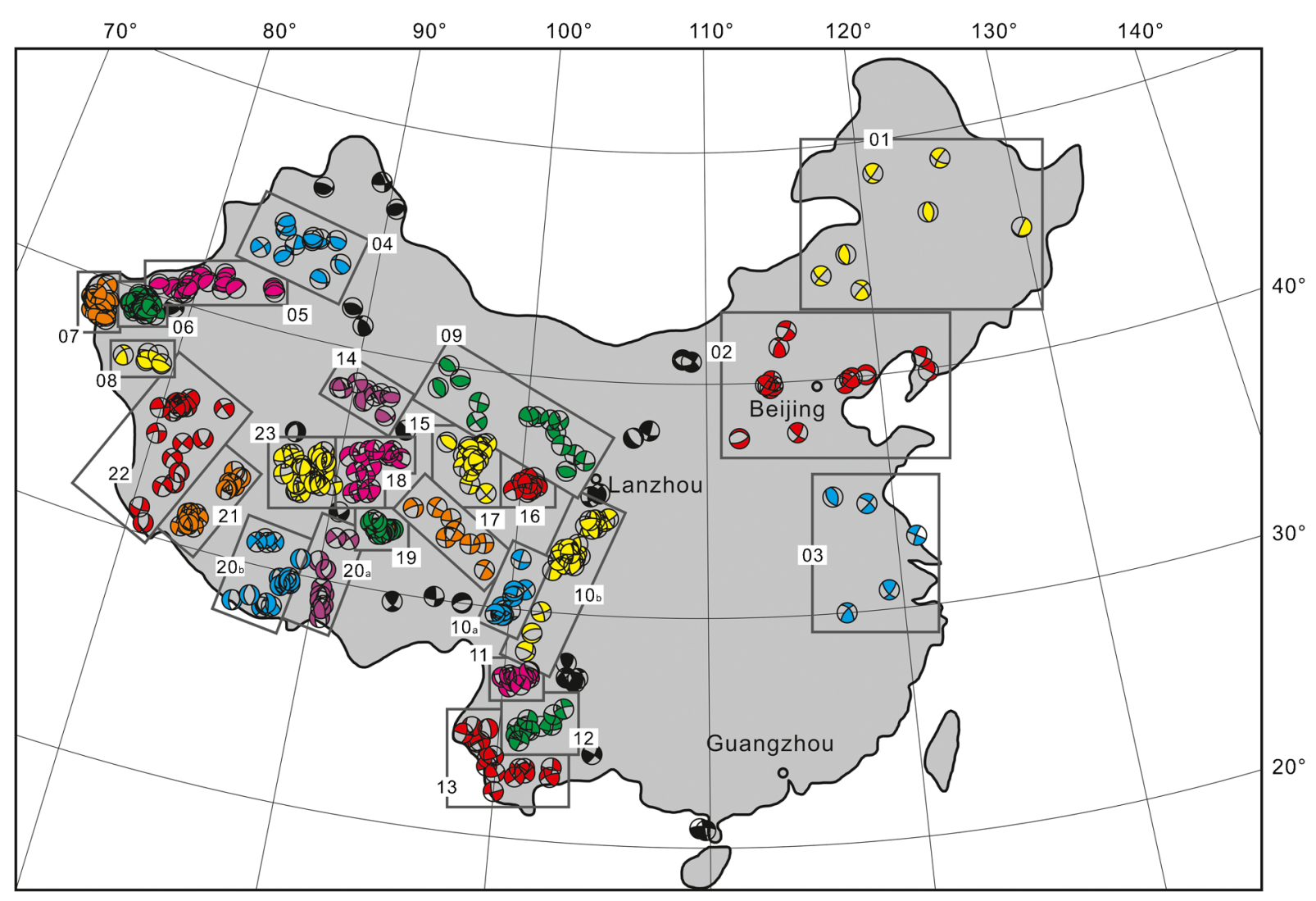

Figure 3. Focal mechanism data assembled into boxes for stress inversion. Boxes - 1: northeastern China region; 2 : northern China region; 3: eastern China region; 4: southwest Junggar Basin; 5: Aksu region; 6: eastern Kaxgar region; 7: western Kaxgar region; 8: Hotan region; 9: Gansu region; 10: Sichuan region; 11: northwestern Yunnan region; 12: northern Yunnan region; 13: southwestern Yunnan region; 14: northwestern Qinghai region; 15: central Qinghai region; 16: eastern Qinghai region; 17: southern Qinghai region; 18: southwestern Qinghai region; 19: eastern Tibet region; 20: southern Tibet region; 21: southwestern Tibet region; 22: western Tibet region; 23: northeastern Tibet region. 
It forms a continuous scale ranging from 0 to 1 for normal faulting regimes, 1 to 2 for strikeslip regimes and 2 to 3 for thrust faulting regimes (figure 2; Delvaux et al. 1995, 1997; Zhang and Wang 2004; Cortes and Angelier 2005; Delvaux and Barth 2010).

\section{Present-day tectonic stress field}

\subsection{Results}

In the present study, the present-day tectonic stress field and stress regime for each focal mechanism in the Chinese Mainland were studied based on the above method (figures 3, 4 and 5). The results indicated that (a) the average $\sigma_{1}$ orientation was $\sim \mathrm{E}-\mathrm{W}$-trending in the eastern Chinese Mainland (box-1-box-3), which agreed with previous studies (e.g., Yao et al. 1991; Xie et al. 2004). The stress regime was dominated by the SS, (b) the northwestern Chinese Mainland (box-4-box-8) was characterized with a TF regime, and the $\sigma_{1}$ orientations ranged between NNW-SSE-trending and NNE-SSWtrending, (c) the Yunnan region (box-11-box-13) was dominated by a SS regime with NNW-SSEtrending to NNE-SSW-trending $\sigma_{1}$ orientations, (d) the southern Tibet region (box-20-box-22) was characterized with a NF regime, and the average $\sigma_{1}$ orientation was $\sim \mathrm{N}-\mathrm{S}$-trending, (e) the regions of Gansu and Qinghai (box-9-box-10 and box-14box-17) were dominated by a $\mathrm{TF}$ regime with $\mathrm{NE}-$ SW-trending to NEE-SWW-trending $\sigma_{1}$ orientations, and (f) the northern Tibet region (box-18, box-19 and box-23) was characterized by NF and SS regimes, the $\sigma_{1}$ orientations varied between NNE-SSW-trending and NE-SW-trending.

\subsection{Analysis of the misfit}

In general, focal mechanisms have different values due to the number and distribution of recording stations, magnitude, determination technique, etc., it is important to check the stability obtained as a function of datum weight and quality (Audemard et al. 2005; Cortes and Angelier 2005). The quality evaluation of the results was done using the updated quality ranking system of the World Stress Map release 2008 (Delvaux and Barth 2010; Heidbach et al. 2010). It evaluates the azimuthal accuracy of $\mathrm{S}_{\mathrm{H} \max }$ obtained from the inversion of a well-constrained focal mechanism ( $N$ is the number of data in equation 6) with an average misfit angle $\alpha$ in close geographic proximity. In addition, the graphical output of the stress tensor is in an equal-area projection, which allows the evaluation of the overall quality.

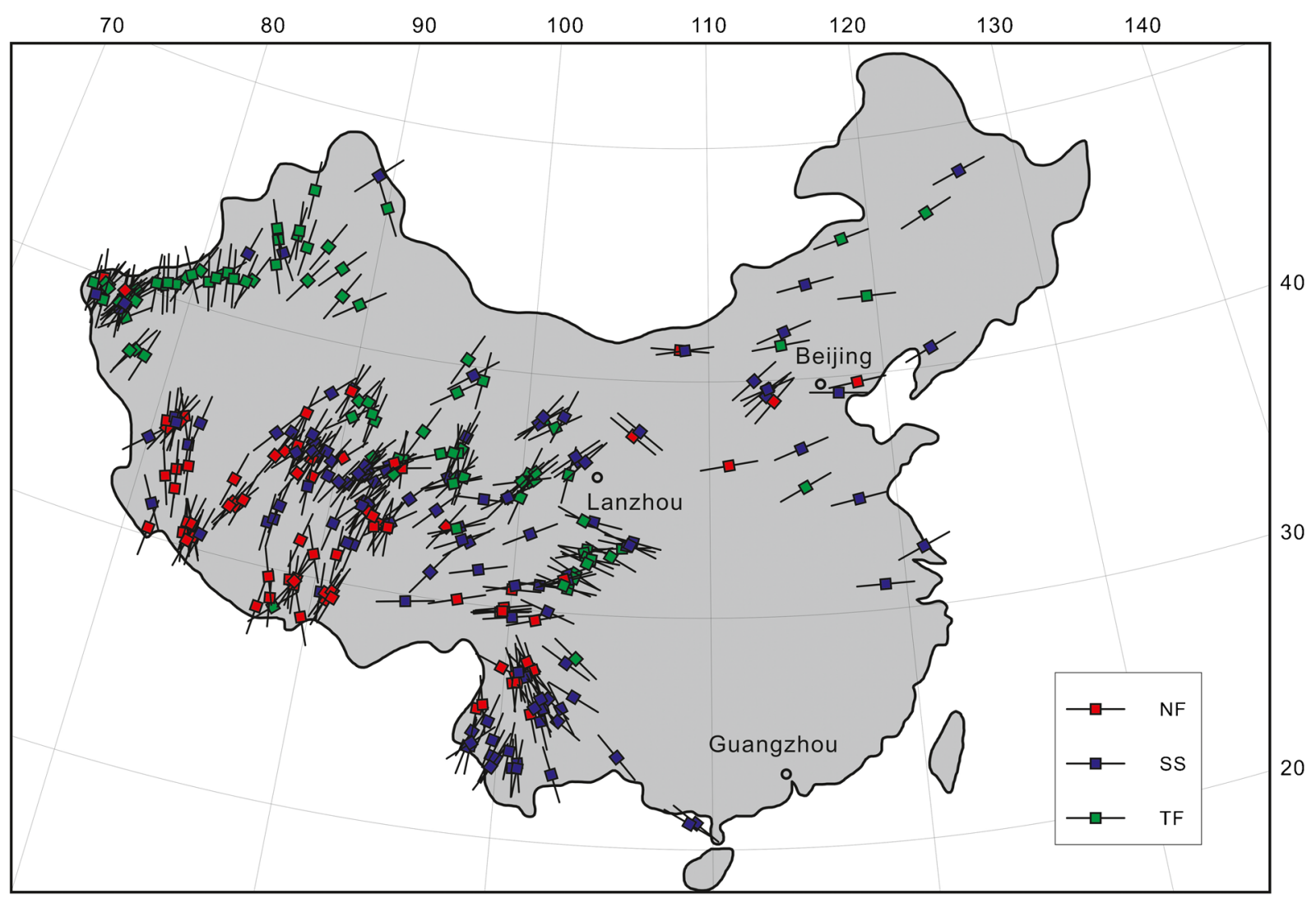

Figure 4. Focal mechanism data represented as $\mathrm{S}_{\mathrm{Hmax}}$ axes. A colour-coded central square indicates the tectonic regime red: NF; blue: SS; green: TF. 
A-quality:

$\mathrm{S}_{\text {Hmax }} / \mathrm{S}_{\text {hmin }}$ within $\pm 15^{\circ} ; N \geq 15$ and $\alpha \leq 12^{\circ}$;

B-quality:

$\mathrm{S}_{\mathrm{Hmax}} / \mathrm{S}_{\mathrm{hmin}}$ within $\pm 15-20^{\circ} ; 15 \geq N \geq 8$ and $12 \leq \alpha \leq 20^{\circ}$
C-quality:

$\mathrm{S}_{\mathrm{Hmax}} / \mathrm{S}_{\mathrm{hmin}}$ within $\pm 20-25^{\circ} ; 8 \geq N \geq 6$ and

$20<\alpha$.

In the present study, the average misfit ranged from 5.21 to 12.41 , indicating that the qualities of

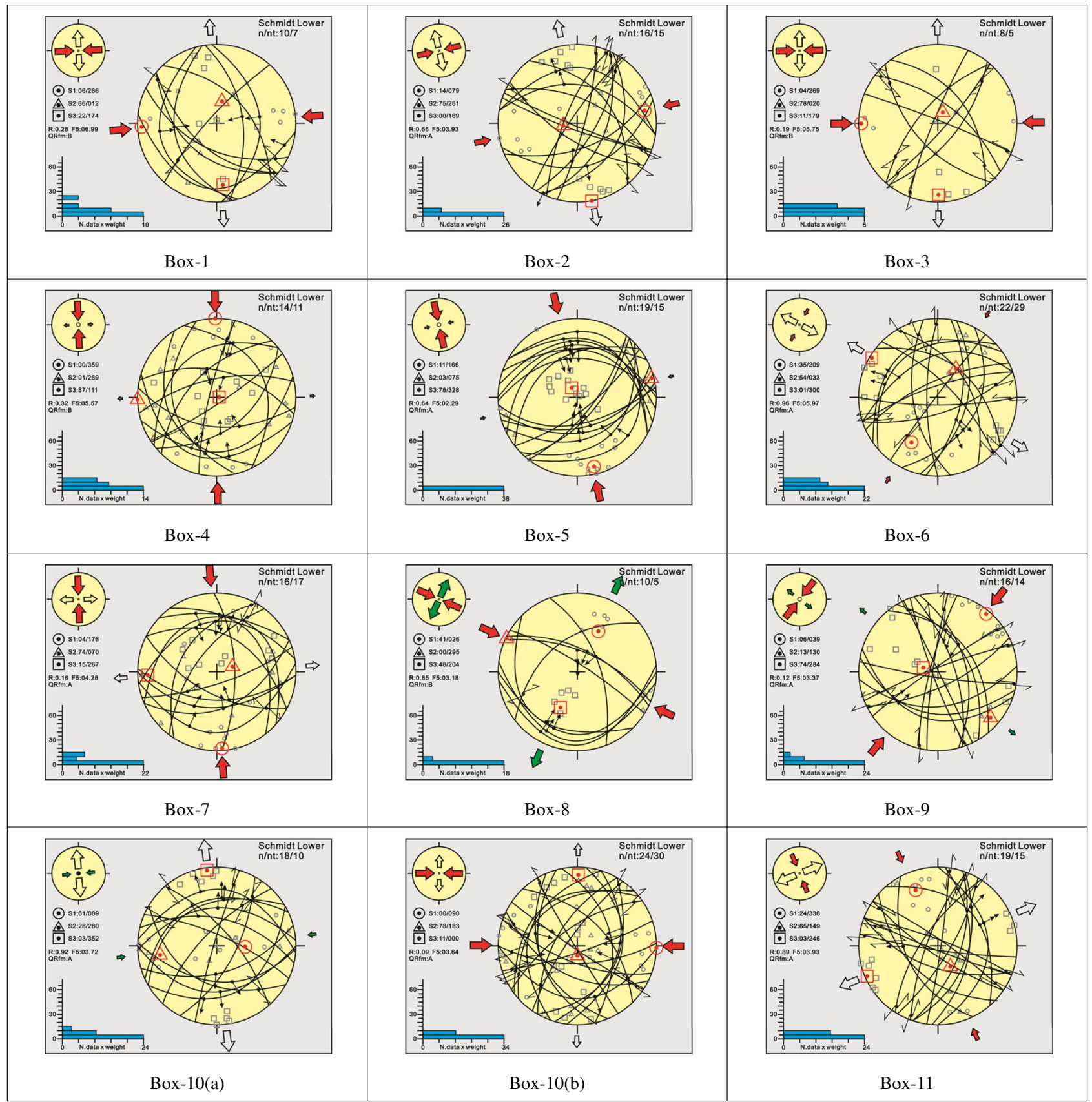

Figure 5. Lower-hemisphere equal-area stereo-plots of the selected focal planes and associated slip lines (black dot with outward arrow for normal faulting, inward arrow for reverse faulting and double semi-arrows for strike-slip faulting). Stress inversion results are represented by the orientation of the three principal stress axes (a dot surrounded by a circle for $\sigma_{1}$, a triangle for $\sigma_{2}$, and a square for $\sigma_{3}$ ). The related $\mathrm{S}_{\mathrm{Hmax}}$ and $\mathrm{S}_{\mathrm{hmin}}$ orientations are represented by large arrows outside the stereogram. White arrows: $\sigma_{3}$ is sub-horizontal, green arrows: $\sigma_{2}$ is sub-horizontal and red arrows: $\sigma_{1}$ is sub-horizontal. Outward arrow indicates extensional deviatoric stress and inward arrows for compressional deviatoric stress. The vertical stress is symbolized in the small circle on the upper left corner of the figures by a solid circle for extensional regimes, a dot for strike-slip regimes and an open circle for compressional regimes. The histogram on the lower left corner of the figures represents the distribution of the misfit angle, weighted arithmetically according to the magnitude. 


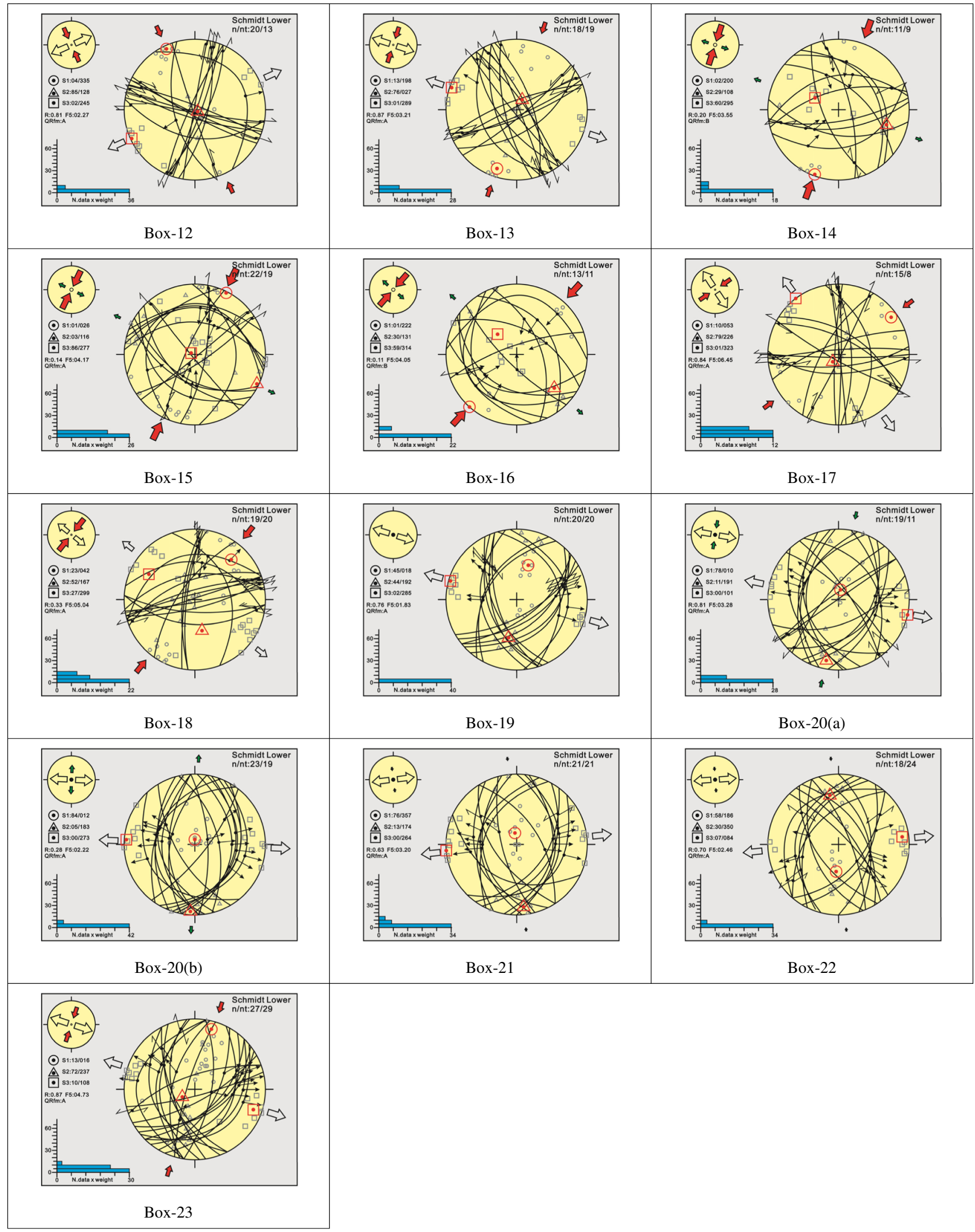

Figure 5. (Continued.)

all the boxes fell into B- or A-level (table 1 and figure 5). Generally, A-, B- and C-quality stress indicators are considered reliable for the use in analyzing stress patterns and the interpretation of geodynamic processes (Naimi-Ghassabian et al. 2015); therefore, the present results are reliable. 
Table 1. Stress inversion results for the 23 boxes (parameters for stress map).

\begin{tabular}{|c|c|c|c|c|c|c|c|c|c|c|c|c|c|c|c|}
\hline \multicolumn{3}{|c|}{ Box definition } & \multicolumn{7}{|c|}{ Reduced stress tensor parameters } & \multicolumn{2}{|c|}{$\mathrm{SH}$} & \multicolumn{4}{|c|}{ Misfit, regime and quality rank } \\
\hline No. & Location & Data & $\sigma_{1} \mathrm{pl}$ & $\sigma_{1} \mathrm{az}$ & $\sigma_{2} \mathrm{pl}$ & $\sigma_{2} \mathrm{az}$ & $\sigma_{3} \mathrm{pl}$ & $\sigma_{3} \mathrm{az}$ & $R$ & Max & Min & Misfit (aver) & $R^{\prime}$ & Regime & 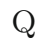 \\
\hline & Northeastern China region & 7 & 06 & 266 & 66 & 012 & 22 & 174 & 0.28 & 086 & 176 & 12.41 & 1.72 & SS & \\
\hline 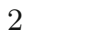 & Northern China region & 15 & 14 & 079 & 75 & 261 & 00 & 169 & 0.66 & 079 & 169 & & 1.34 & SS & \\
\hline 3 & Eastern China region & 5 & 04 & 269 & 78 & 020 & 11 & 17 & 0.19 & 090 & 000 & 9 & 1.81 & SS & $\mathrm{E}$ \\
\hline & Southwestern Junggar Basin & 11 & 00 & 359 & 01 & 269 & 87 & 11 & 0.32 & 179 & 089 & 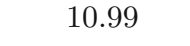 & 2.32 & $\mathrm{TF}$ & B \\
\hline 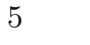 & Aksu region & 15 & 11 & 166 & 03 & 075 & 78 & 3 & 0.64 & 167 & 077 & & 2.64 & $\mathrm{TF}$ & A \\
\hline & Eastern Kaxga & 29 & 35 & 209 & 54 & 033 & 01 & 300 & 96 & 031 & 121 & & 1.04 & SS & \\
\hline & Western Ka & 17 & 04 & 176 & 74 & 070 & 15 & & 0.16 & 176 & 086 & & 1.84 & SS & \\
\hline & Hotan region & 5 & 41 & 026 & 00 & 295 & 48 & 20 & 0.85 & 115 & 025 & 6. & 2.85 & UF & $\mathrm{E}$ \\
\hline & Gansu region & 14 & 06 & 039 & 13 & 130 & 74 & 28 & 2 & 039 & 129 & & 2.12 & TF & \\
\hline $0(\mathrm{a})$ & Sichuan regi & & 61 & 089 & 28 & 260 & 03 & 352 & 2 & 083 & 173 & & 0.92 & NF & \\
\hline $0(\mathrm{~b})$ & Sichuan region & 3 & 00 & 090 & $7 \varepsilon$ & 183 & 11 & 00 & 9 & 091 & 001 & & 1.91 & & \\
\hline 11 & Northwestern Yunnan region & 15 & 24 & 338 & 65 & 149 & 03 & 24 & 0.89 & 157 & 067 & 9.49 & 1.11 & S & \\
\hline 2 & Northern Yunnan region & 13 & 04 & 335 & 85 & 128 & 02 & 245 & 0.81 & 155 & 065 & 5.71 & 1.19 & SS & \\
\hline 13 & Southwestern Yunnan region & 19 & 13 & 198 & 76 & 027 & - & & & 019 & 109 & & 1.13 & & \\
\hline 14 & Northwestern Qinghai region & 9 & 02 & 200 & 2 & 10 & 6 & 29 & 0 & 020 & 110 & & 2.20 & $\mathrm{TF}$ & \\
\hline 15 & Central Qinghai region & 19 & 01 & 026 & 03 & 116 & 86 & 277 & 0.14 & 026 & 116 & 9.25 & 2.14 & $\mathrm{TF}$ & \\
\hline 16 & Eastern Qinghai region & 11 & 01 & 222 & 30 & 131 & 59 & 314 & 0.11 & 042 & 132 & 7.93 & 2.11 & $\mathrm{TF}$ & \\
\hline 17 & Southern Qinghai region & 0 & 10 & 053 & 79 & 226 & 01 & 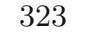 & 4 & 054 & 144 & & 1.16 & N & \\
\hline 10 & Southwestern Qinghai region & 20 & 23 & & 52 & 16 & 27 & & & 039 & 129 & & 1.67 & UF & \\
\hline 19 & Eastern Tibet region & 20 & 45 & 018 & 44 & 192 & 02 & 285 & 6 & 016 & 106 & 5.21 & 0.76 & NS & \\
\hline $20(\mathrm{a})$ & Southern Tibet region & 11 & 78 & 010 & 11 & 191 & 00 & 101 & 0.81 & 012 & 102 & 7.86 & 0.81 & NF & \\
\hline $20(\mathrm{~b})$ & Southern Tibet region & 19 & 84 & 012 & 05 & 183 & 00 & 273 & 0.28 & 003 & 093 & 5.55 & 0.28 & NF & \\
\hline 21 & Southwestern Tibet re & 21 & 76 & 357 & 13 & 174 & 00 & & & 174 & 084 & 7.64 & 0.63 & NF & \\
\hline 22 & Western Tibet region & 24 & 58 & 186 & 30 & 350 & 07 & 084 & 0.70 & 175 & 085 & 6.47 & 0.70 & NF & \\
\hline 23 & Northeastern Tibet region & 29 & 13 & 016 & 72 & 237 & 10 & 108 & 0.87 & 018 & 108 & 9.86 & 1.13 & SS & \\
\hline
\end{tabular}

Note: Box definition: box number, location and the number of data in the box; Reduced stress tensor parameters: plunge $(\mathrm{pl})$ and azimuth $(\mathrm{az})$ of the principal stress axes $\left(\sigma_{1}, \sigma_{2}\right.$ and $\left.\sigma_{3}\right)$ and stress ratio $R ; \mathrm{SH}$ : $\mathrm{S}_{\mathrm{Hmax}}$ and $\mathrm{S}_{\mathrm{hmin}}$; misfit, regime and quality rank: average misfit angle, regime as in figure $2, \mathrm{Q}$ - quality rank as in equation (6).

\section{Discussion}

\subsection{Tectonic stress regime}

The tectonic stress regime in the Chinese Mainland was analyzed (figures 6 and 7 ) based on stress ratio $R$ and stress index $R^{\prime}$ (equation 5 and figure 2).

The stress inversion results of box-10(a), box-20 (a, b), box-21 and box-22 indicated a NF regime with $R^{\prime}$ ranging from 0.28 to 0.92 (table 1 ). Values close to 0.50 denote a pure NF regime (figure 2; e.g., 0.63 for box-21: southwestern Tibet region), close to 0 denote a tendency towards radial extension (figure 2; e.g., 0.28 for box-20(b): southern Tibet region), and close to 1.00 indicate the presence of a strike-slip component (figure 2; 0.92 for box-10(a): Sichuan region).

The stress inversion results of box-1, box-2, box-3, box-6, box-7, box-10(b), box-11, box-12, box-13, box-17 and box-23 indicated a SS regime with $R^{\prime}$ ranging from 1.04 to 1.91 (table 1 ). Values close to 1.50 denote a pure SS regime (figure 2; e.g., 1.34 for box-2: North China region), close to 1.00 denote a tendency towards extension (figure 2; e.g., 1.04 for box-6: eastern Kaxgar region), and close to 2.00 denote a tendency towards compression (figure 2; 1.91 for box-10(b): Sichuan region).

The stress inversion results of box- 4 , box- 5 , box- 9 , box-14, box-15 and box-16 indicated a TF regime with $\mathrm{R}^{\prime}$ ranging from 2.11 to 2.64 (table 1 ). Values close to 2.50 denote a pure TF regime (figure 2; e.g., 2.64 for box-5: Aksu region), close to 2.00 indicate the presence of a strike-slip component (figure 2; e.g., 2.11 for box-16: eastern Qinghai region and 2.12 for box-9: Gansu region), and close to 3.00 denote a tendency towards radial compression.

To sum up, in the Chinese Mainland, the southwestern regions were mainly extensional regime, the northwestern regions were compressional regime, and strike-slip regime occurred mainly in the middle and eastern regions (figure 7).

\subsection{Tectonic models and GPS observations}

From the perspective of tectonic location, the majority of the Chinese Mainland belongs to Eurasian plate, and it is adjacent to Pacific plate on the east, Indian plate on the southwest 


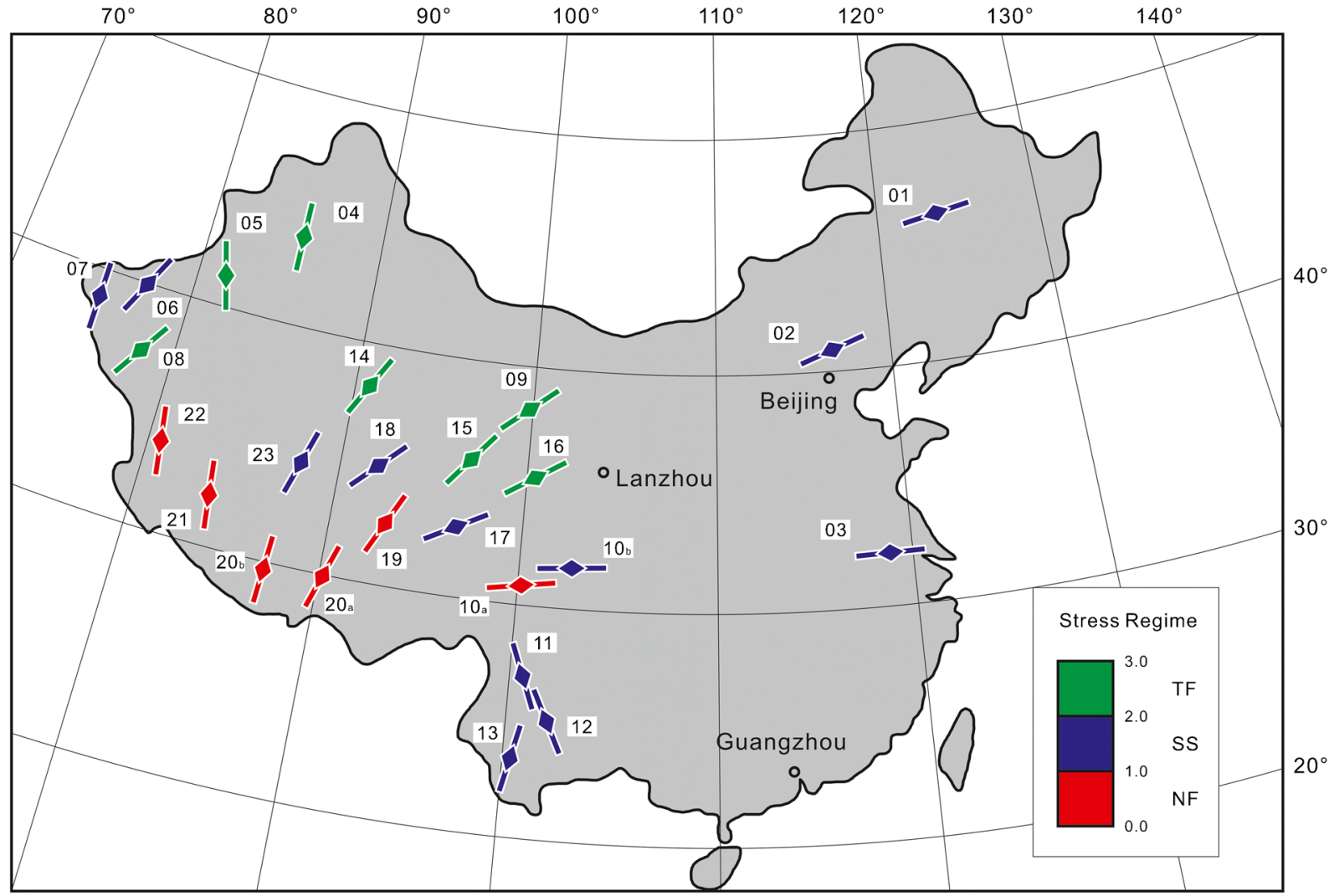

Figure 6. Map representation of the stress inversion results for each box in the Chinese Mainland. Stress regime - green: TF, blue: SS and red: NF.

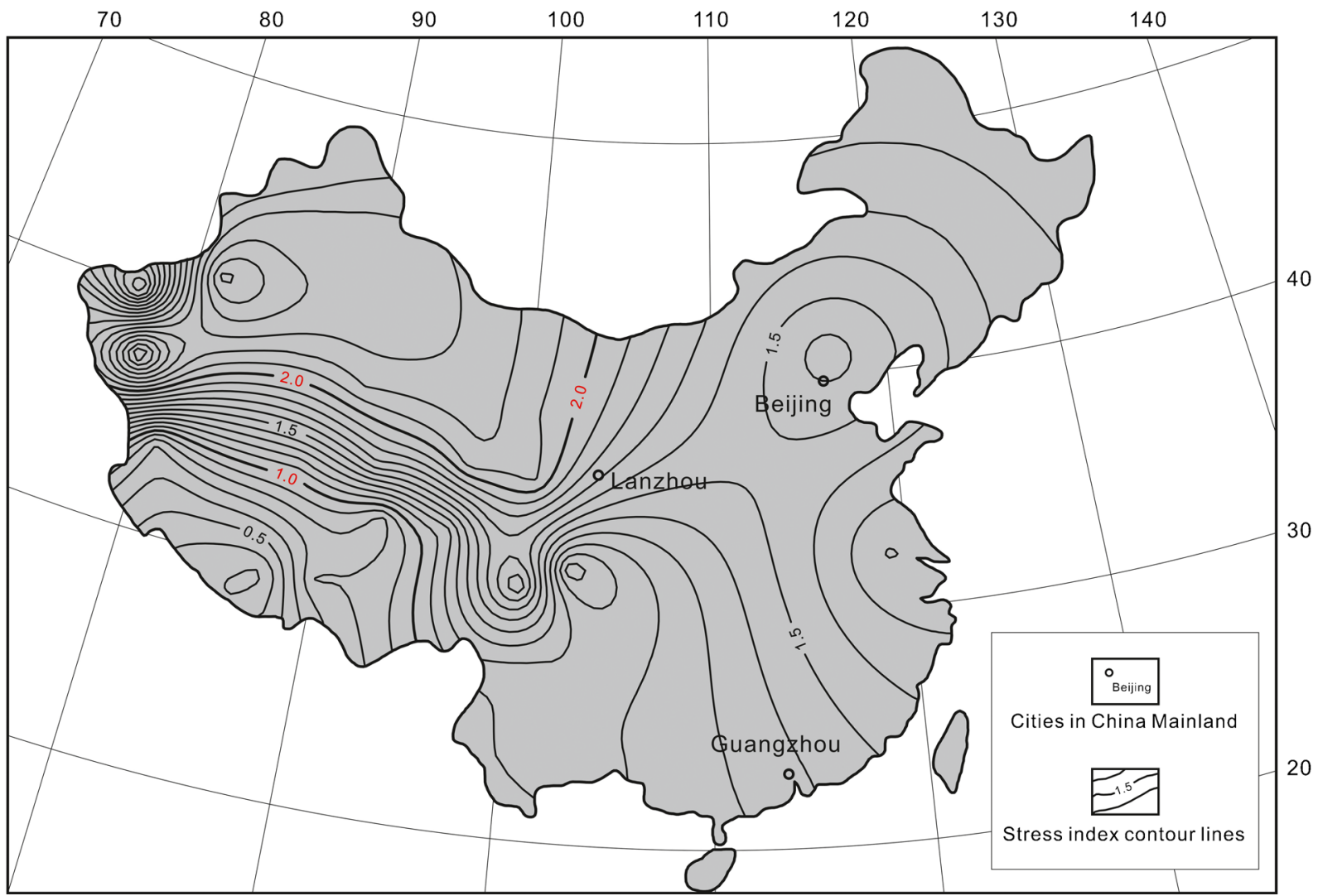

Figure 7. Stress index $\left(R^{\prime}\right)$ counter diagram in the Chinese Mainland. $0 \leq R^{\prime} \leq 1$, extensional regime; $1 \leq R^{\prime} \leq 2$, strike-slip regime; $2 \leq R^{\prime} \leq 3$, compressional regime. 
(Tapponnier and Molnar 1977; Wang et al. 1996; Yin 2010). Because of this special tectonic location, the mutual action among Eurasian plate, Pacific plate and Indian plate must have a great impact on the tectonic stress field of Chinese Mainland during the neotectonics period (Deng et al. 1979; Wang et al. 1996; Xu and Zhao 2006; Yin 2010). Among them, the India-Eurasia collision and continuous northward movement of the Indian plate play a dominant role in controlling the tectonic movement and present-day tectonic stress environment of Chinese Mainland (e.g., Tapponnier and Molnar 1977; Deng et al. 1979; Tapponnier et al. 1982; Yin 2010). Tapponnier et al. (1982) modelled the India-Eurasia collision with plasticine layers (Eurasia) and steel piston (India) and proposed the 'Extrusion Model' for the tectonics of Asia (figure 8). Generally, the present study results and GPS velocities in the Chinese Mainland (figure 9) support and agree with Tapponnier's model, which may provide new insights into the tectonic models.

The Tibetan plateau underwent substantial internal shortening with an average $\sim 40 \mathrm{~mm} / \mathrm{yr}$ convergence rate in the direction of about NE20' (figure 9). The southern Tibet region was characterized by a series of $\sim \mathrm{N}$-S-trending normal faults and grabens in a NF regime (figure 4; Tapponnier and Molnar 1977; Yin 2010). GPS measurements indicated that the extensional rate across southern Tibet was about $20 \mathrm{~mm} / \mathrm{yr}$ (Wang et al. 2001; Zhao 2015). Regions in the eastern Tibetan plateau showed a prominent clockwise rotation around the Eastern Himalayan Syntaxis (figure 9; Holt et al. 2000; Wang et al. 2001; Yin 2010). In general, it was $\sim \mathrm{E}-\mathrm{W}$-trending in western Sichuan, $\sim \mathrm{SE}-$ NW-trending in northern Yunnan, $\sim \mathrm{SSE}-\mathrm{NNW}$ trending in southern Yunnan and $\sim \mathrm{N}-\mathrm{S}$-trending in western Yunnan (figure 9). In the northwestern Chinese Mainland, widespread active tectonics and high seismicity attested to rapid crustal shortening. In this region, the total shortening rate in the western part was higher $(\sim 20 \mathrm{~mm} / \mathrm{yr}$ in the west and $\sim 2 \mathrm{~mm} / \mathrm{yr}$ in the east), which was consistent with the conclusion of eastward decreases of crustal shortening based on geological investigations and theoretical modelling (Wang et al. 2001). In the North China region, the GPS measurements indicated a $\sim$ SEE-NWW-trending movement at rates of $2 \sim 8 \mathrm{~mm} / \mathrm{yr}$. The majority of active faults in the North China region were in the NNE-SSW direction, which intersected with the south-southeastward movement would probably produce right-lateral strike-slip components. These components resulted in major earthquakes (Wang et al. 2001). In South China, an average velocity of $6 \sim 11 \mathrm{~mm} / \mathrm{yr}$ with respect to stable Eurasia oriented toward near the eastern direction (figure 9). In addition, the South China was generally considered as a rigid block with rare internal deformations (Holt et al. 2000) and earthquakes.

\subsection{Driving forces}

According to the present analysis and previous studies (e.g., Deng et al. 1979; Xu and Zhao 2006), the driving forces for the present-day tectonic stress field in the Chinese Mainland can be divided into two parts on the basis of plate tectonics.

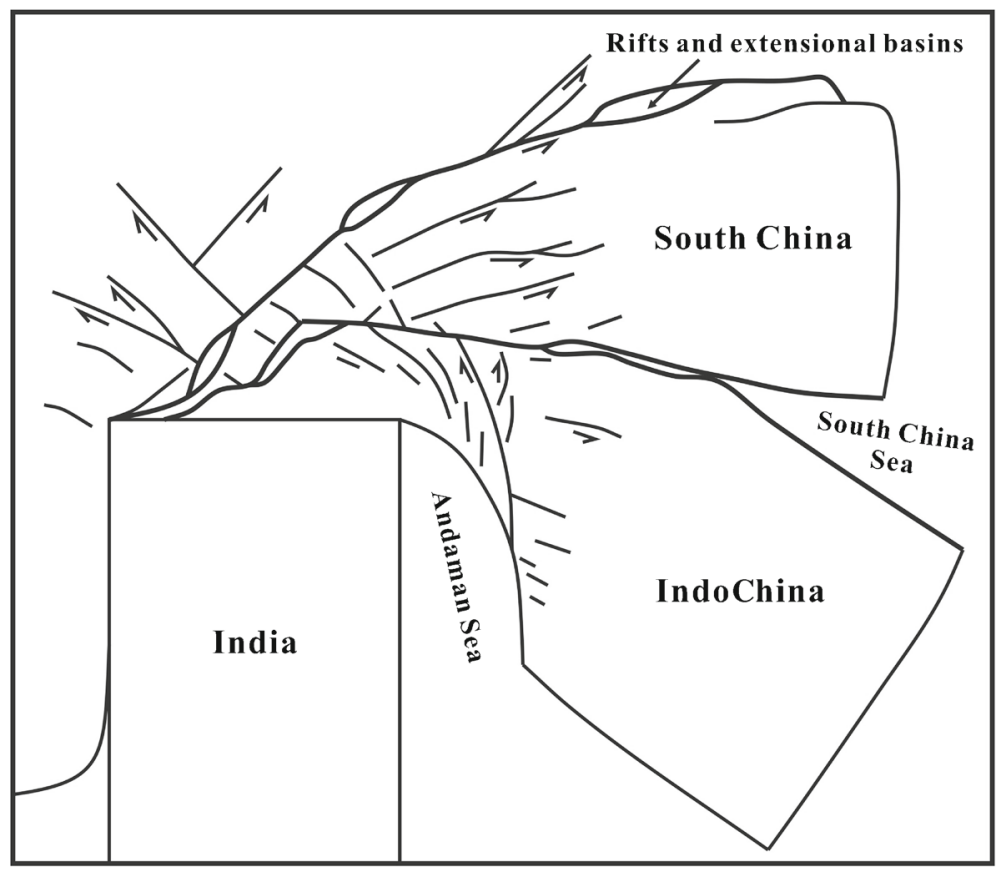

Figure 8. Hand drawings of faults observed in experiments (after Tapponnier et al. 1982). 
In the western Chinese Mainland, the collision between Indo-Australian plate and the Eurasian plate caused the stress field and dominated the movements from the Himalayas to Tianshan Mountains. Thrust-type strong earthquakes occurred frequently along the edges of the Qinghai-Tibet Plateau and in the Tianshan region, and a $\sim \mathrm{E}-\mathrm{W}-$ trending extensional motion with a NF regime apparently occurred in the southern Tibet region (Tapponnier and Molnar 1977; Tapponnier et al. 1986; Xie et al. 1999, 2004; Wang et al. 2001; Xu and Zhao 2006; figure 4). The average $\sigma_{1}$ orientation was $\sim \mathrm{N}$-S-trending in the southern Tibet region, and $\sim \mathrm{NNW}-\mathrm{SSE}$-trending in the Yunnan region due to the resistance of Sichuan Basin and the existing of strike-slip fault nearby. In addition, in the Xinjiang region, remote effects of the collision between India and Eurasian plate caused the $\sigma_{1}$ orientation varied from $\sim \mathrm{NNW}$-SSE-trending to $\sim \mathrm{NNE}-\mathrm{SSW}$-trending (figure 4 ).

In the eastern Chinese Mainland, the presentday stress field was produced by a joint action from the subduction of Pacific plate and the collision between India and Eurasian plate (Deng et al. 1979; Yin and Nie 1993; Xie et al. 1999, 2004).
In addition, the present-day tectonic stress field in the eastern Chinese Mainland started in the Late Miocene, while in the western part, it began at the end of Early Pleistocene. The time difference was determined by the tectonic evolution and geological surroundings (Xie and Liu 1989; Xie et al. 1999; Zhang 1999).

\section{Conclusions}

In this study, the present-day tectonic stress field and stress pattern in the Chinese Mainland were analyzed with 421 earthquake focal mechanism data, and the tectonic regimes and driving forces were also discussed.

The $\sigma_{1}$ orientation varied greatly across the Chinese Mainland. Because of the collision between the Indian and Eurasian plate, the $\sigma_{1}$ orientation in the western Chinese Mainland varied between NW-SE-trending and NE-SW-trending, whereas in the eastern part, joint actions of the Pacific plate subduction and the collision between the Indian and Eurasian plate caused the $\sim \mathrm{E}-\mathrm{W}$-trending $\sigma_{1}$ orientation. In addition, the present study results combined with GPS velocities in the

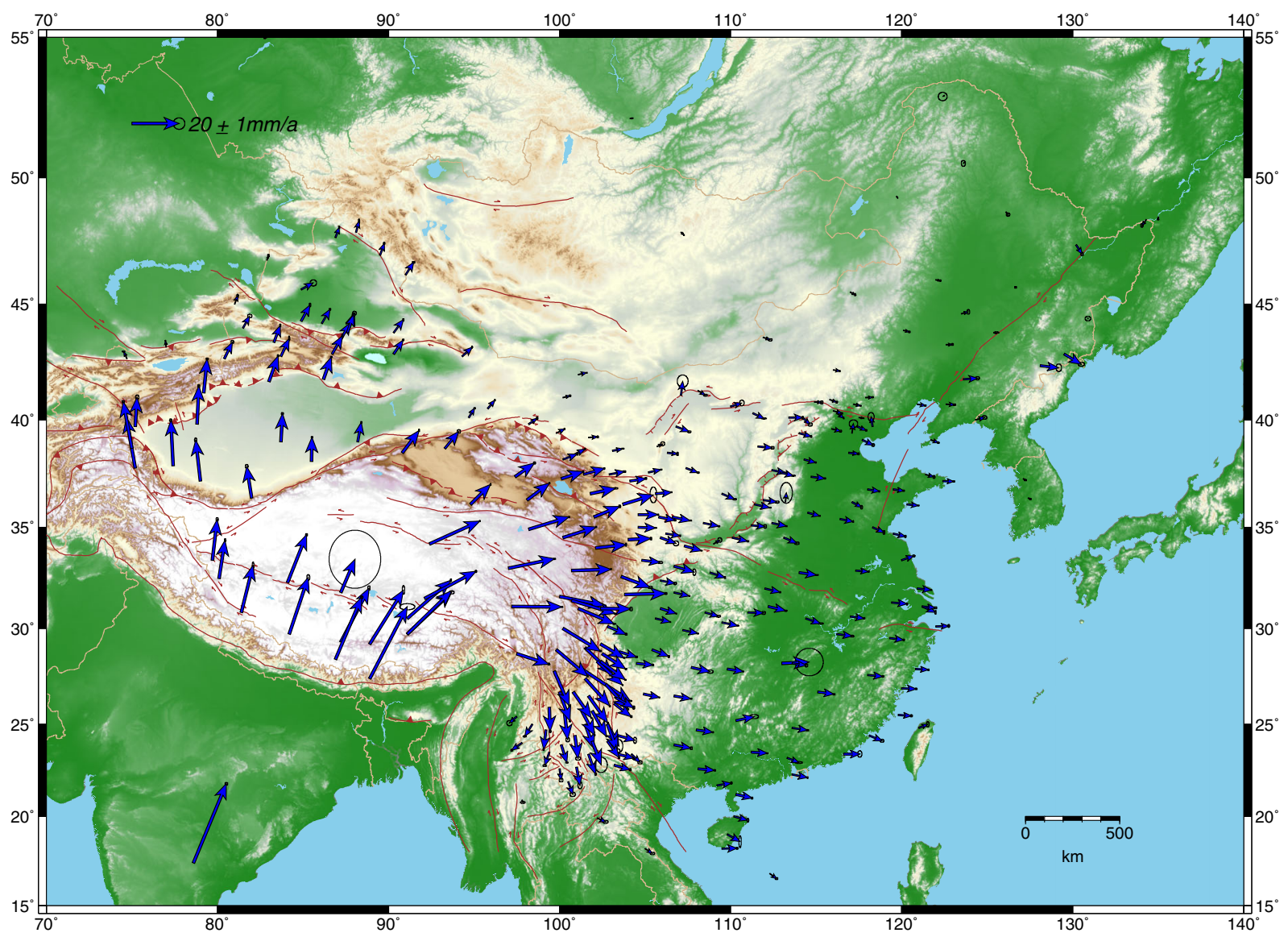

Figure 9. GPS velocity vectors (mm/yr) with respect to the stable Eurasia plotted on a relief map of the Asia topography (after Zhao 2015). 
Chinese Mainland supported and provided new insights intoprevious tectonic models (e.g., the Tapponnier's extrusion model).

The tectonic stress regime showed variations in different regions of Chinese Mainland. In the eastern Chinese Mainland, the dominant was a SS stress regime, whereas the western part was relatively complex. It was a $\mathrm{NF}$ regime in the southern Tibet, SS regime in the northern Tibet, western Xinjiang and Yunnan regions, and TF regime in the majority of Xinjiang, Qinghai and Gansu regions.

\section{Acknowledgements}

We would like to express our gratitude to the anonymous reviewers for offering constructive comments which improved this manuscript in many aspects. Prof. Damien Delvaux and Saibal Gupta are thanked for the program and publication, respectively. This work was supported by the Fundamental Research Funds for the Central Universities (No. 2015QNA69) and the Priority Academic Program Development of Jiangsu Higher Education Institutions.

\section{Appendix}

Table A1. Compiled data base of focal mechanisms used in this study grouped in 23 boxes.

\begin{tabular}{|c|c|c|c|c|c|c|c|c|c|c|}
\hline \multirow{2}{*}{$\begin{array}{l}\text { Data-time group } \\
\text { Event }\end{array}$} & \multicolumn{3}{|c|}{ Location } & \multicolumn{4}{|c|}{ Focal mechanism data } & \multicolumn{2}{|c|}{$\mathrm{SH}$} & \multirow{2}{*}{$\begin{array}{l}\text { Stress } \\
\text { regime }\end{array}$} \\
\hline & Longitude & Latitude & Depth & $\overline{\mathrm{Mw}}$ & Strike & Dip & Slip & $\overline{\operatorname{Max}}$ & $\operatorname{Min}$ & \\
\hline Northeastern China region (Box-1) & 7 & & & & & & & & & \\
\hline CM19800210-04:46:10 & 120.97 & 48.66 & 15.0 & 5.1 & 130 & 54 & 006 & 083 & 173 & UF \\
\hline CM19860815-20:20:39 & 126.09 & 48.61 & 15.0 & 5.0 & 116 & 63 & -012 & 074 & 164 & SS \\
\hline CM19990129-05:44:25 & 116.37 & 44.67 & 15.0 & 5.0 & 130 & 64 & -002 & 085 & 175 & SS \\
\hline CM20020915-08:39:36 & 130.04 & 44.77 & 589.4 & 6.4 & 098 & 19 & 163 & 152 & 062 & UF \\
\hline CM20030816-10:58:46 & 119.47 & 43.80 & 30.0 & 5.4 & 317 & 57 & 010 & 093 & 003 & $\mathrm{TF}$ \\
\hline CM20040324-01:53:51 & 118.15 & 45.38 & 13.0 & 5.3 & 167 & 28 & 086 & 079 & 169 & $\mathrm{TF}$ \\
\hline CM20050725-15:43:38 & 124.88 & 46.86 & 12.0 & 5.0 & 355 & 45 & 093 & 070 & 160 & $\mathrm{TF}$ \\
\hline Northern China region (Box-2) & 15 & & & & & & & & & \\
\hline CM19760727-19:42:11 & 118.03 & 39.52 & 15.0 & 7.6 & 229 & 43 & -163 & 075 & 165 & UF \\
\hline CM19760728-10:45:46 & 118.78 & 39.75 & 15.0 & 7.0 & 072 & 44 & -110 & 086 & 176 & NF \\
\hline CM19761115-13:53:07 & 117.71 & 39.45 & 15.0 & 6.4 & 318 & 56 & -009 & 097 & 007 & SS \\
\hline CM19770512-11:17:54 & 118.00 & 39.56 & 22.0 & 5.7 & 322 & 52 & 008 & 102 & 012 & UF \\
\hline CM19780518-12:33:34 & 122.56 & 40.79 & 15.0 & 5.5 & 023 & 60 & -177 & 067 & 157 & SS \\
\hline CM19790619-04:15:09 & 111.50 & 36.83 & 33.0 & 5.0 & 278 & 30 & -063 & 084 & 174 & NF \\
\hline CM19811108-18:01:08 & 115.09 & 37.08 & 15.0 & 5.6 & 031 & 72 & 162 & 079 & 169 & SS \\
\hline CM19891018-14:57:27 & 113.61 & 39.83 & 15.0 & 5.4 & 204 & 76 & -176 & 068 & 158 & SS \\
\hline CM19891018-17:01:39 & 113.49 & 39.77 & 15.0 & 5.6 & 200 & 75 & -175 & 065 & 155 & SS \\
\hline CM19891018-18:20:50 & 113.84 & 39.63 & 15.0 & 5.4 & 092 & 44 & -039 & 062 & 152 & NF \\
\hline CM19910325-18:02:44 & 113.34 & 40.10 & 15.0 & 5.4 & 106 & 82 & 007 & 060 & 150 & SS \\
\hline CM19980110-03:50:46 & 114.34 & 41.34 & 15.0 & 5.7 & 207 & 54 & 135 & 086 & 176 & $\mathrm{TF}$ \\
\hline CM19990311-13:18:13 & 114.64 & 41.73 & 15.0 & 5.1 & 295 & 65 & -009 & 074 & 164 & SS \\
\hline CM19991101-13:25:19 & 113.74 & 39.85 & 15.0 & 5.2 & 122 & 72 & -007 & 078 & 168 & SS \\
\hline CM20000111-23:43:58 & 123.11 & 40.36 & 15.0 & 5.1 & 027 & 43 & -178 & 071 & 161 & $\mathrm{UF}$ \\
\hline Eastern China region (Box-3) & 5 & & & & & & & & & \\
\hline CM19790709-10:57:25 & 118.99 & 31.11 & 15.0 & 5.4 & 138 & 66 & 022 & 089 & 179 & SS \\
\hline CM19831106-21:09:51 & 115.17 & 35.21 & 21.0 & 5.5 & 142 & 44 & 071 & 065 & 155 & $\mathrm{TF}$ \\
\hline CM19840521-15:39:01 & 121.37 & 32.56 & 24.3 & 6.0 & 202 & 85 & 178 & 066 & 156 & SS \\
\hline CM19950920-03:14:34 & 118.07 & 34.87 & 33.0 & 5.1 & 308 & 69 & -007 & 084 & 174 & SS \\
\hline CM20051126-00:49:38 & 115.71 & 29.66 & 17.8 & 5.2 & 324 & 57 & 023 & 099 & 009 & $\mathrm{UF}$ \\
\hline Southwestern Junggar Basin (Box-4) & 11 & & & & & & & & & \\
\hline CM19780422-15:04:25 & 086.54 & 42.26 & 15.0 & 5.3 & 336 & 38 & 135 & 040 & 130 & $\mathrm{TF}$ \\
\hline CM19801106-01:34:31 & 086.22 & 43.89 & 20.0 & 5.7 & 082 & 18 & 066 & 003 & 093 & $\mathrm{TF}$ \\
\hline CM19830303-03:32:19 & 086.91 & 43.97 & 65.6 & 5.3 & 148 & 38 & 128 & 036 & 126 & $\mathrm{TF}$ \\
\hline CM19831215-10:52:60 & 087.64 & 43.10 & 56.3 & 5.1 & 165 & 44 & 132 & 049 & 139 & $\mathrm{TF}$ \\
\hline CM19901024-23:38:15 & 083.99 & 43.79 & 15.0 & 5.2 & 106 & 48 & 141 & 164 & 074 & $\mathrm{TF}$ \\
\hline CM19950502-11:48:13 & 084.54 & 43.49 & 18.0 & 5.5 & 098 & 57 & 170 & 146 & 056 & SS \\
\hline CM19960109-06:27:59 & 085.47 & 44.01 & 33.0 & 5.4 & 108 & 23 & 118 & 005 & 095 & $\mathrm{TF}$ \\
\hline CM20030213-17:34:28 & 085.41 & 44.04 & 45.2 & 5.3 & 073 & 32 & 064 & 177 & 087 & $\mathrm{TF}$ \\
\hline CM20061123-11:04:47 & 083.47 & 44.26 & 30.4 & 5.1 & 231 & 39 & 052 & 162 & 072 & $\mathrm{TF}$ \\
\hline
\end{tabular}


Table A1. (Continued.)

\begin{tabular}{|c|c|c|c|c|c|c|c|c|c|c|}
\hline \multirow[b]{2}{*}{ Data-time group event } & \multicolumn{3}{|c|}{ Location } & \multicolumn{4}{|c|}{ Focal mechanism data } & \multicolumn{2}{|c|}{$\mathrm{SH}$} & \multirow{2}{*}{$\begin{array}{c}\text { Stress } \\
\text { Regime }\end{array}$} \\
\hline & Longitude & Latitude & $\overline{\text { Depth }}$ & $\overline{\mathrm{Mw}}$ & Strike & Dip & Slip & $\overline{\operatorname{Max}}$ & $\overline{\mathrm{Min}}$ & \\
\hline \multicolumn{11}{|c|}{ Southwestern Junggar Basin (Box-4) } \\
\hline CM20070720-10:06:56 & 082.38 & 42.93 & 25.3 & 5.6 & 324 & 66 & 175 & 011 & 101 & SS \\
\hline CM20080830-12:46:50 & 083.96 & 42.79 & 12.8 & 5.3 & 265 & 39 & 118 & 159 & 069 & $\mathrm{TF}$ \\
\hline Aksu region (Box-5) & 15 & & & & & & & & & \\
\hline CM19770723-06:57:09 & 083.59 & 42.20 & 33.0 & 5.4 & 299 & 19 & 118 & 016 & 106 & $\mathrm{TF}$ \\
\hline CM19780312-08:29:26 & 079.97 & 41.92 & 15.0 & 5.4 & 300 & 27 & 131 & 014 & 104 & $\mathrm{TF}$ \\
\hline CM19790329-02:01:35 & 083.69 & 41.93 & 15.0 & 5.6 & 279 & 29 & 107 & 001 & 091 & $\mathrm{TF}$ \\
\hline CM19801206-02:45:32 & 078.56 & 40.37 & 15.0 & 5.2 & 256 & 20 & 126 & 142 & 052 & $\mathrm{TF}$ \\
\hline CM19870105-22:52:51 & 081.48 & 41.77 & 15.0 & 5.7 & 226 & 21 & 047 & 142 & 052 & $\mathrm{TF}$ \\
\hline CM19870124-08:09:24 & 079.31 & 41.26 & 15.0 & 6.1 & 268 & 45 & 107 & 167 & 077 & $\mathrm{TF}$ \\
\hline CM19870303-09:41:33 & 079.52 & 41.30 & 33.0 & 5.0 & 042 & 21 & 096 & 131 & 041 & $\mathrm{TF}$ \\
\hline CM19910225-14:30:35 & 079.20 & 40.34 & 15.0 & 6.0 & 242 & 40 & 085 & 156 & 066 & $\mathrm{TF}$ \\
\hline CM19940509-09:14:13 & 079.02 & 40.25 & 33.0 & 5.0 & 068 & 45 & 102 & 150 & 060 & $\mathrm{TF}$ \\
\hline CM19940823-14:18:37 & 079.37 & 40.37 & 15.0 & 5.2 & 085 & 35 & 134 & 151 & 061 & $\mathrm{TF}$ \\
\hline CM19950926-04:39:11 & 081.40 & 42.02 & 43.0 & 5.1 & 246 & 38 & 077 & 163 & 073 & $\mathrm{TF}$ \\
\hline CM19980625-06:39:20 & 080.44 & 41.16 & 15.1 & 5.1 & 262 & 27 & 129 & 152 & 062 & $\mathrm{TF}$ \\
\hline CM19980728-04:51:47 & 081.58 & 41.93 & 46.9 & 5.1 & 260 & 42 & 088 & 173 & 083 & $\mathrm{TF}$ \\
\hline CM19990315-10:43:01 & 082.38 & 41.98 & 17.0 & 5.4 & 279 & 19 & 135 & 163 & 073 & $\mathrm{TF}$ \\
\hline CM20090220-10:02:32 & 078.63 & 40.74 & 16.6 & 5.3 & 262 & 36 & 091 & 171 & 081 & $\mathrm{TF}$ \\
\hline Eastern Kaxgar region (Box-6) & 29 & & & & & & & & & \\
\hline CM19771218-16:47:22 & 077.44 & 39.92 & 15.0 & 5.9 & 286 & 27 & 125 & 041 & 131 & $\mathrm{TF}$ \\
\hline CM19850823-08:33:05 & 076.46 & 39.31 & 15.0 & 5.0 & 308 & 85 & 175 & 173 & 083 & SS \\
\hline CM19931130-20:37:27 & 076.50 & 39.73 & 19.0 & 5.6 & 219 & 74 & 004 & 173 & 083 & SS \\
\hline CM19940112-10:22:58 & 076.53 & 39.15 & 32.0 & 5.5 & 298 & 60 & 151 & 170 & 080 & SS \\
\hline CM19960319-15:00:36 & 076.80 & 39.93 & 22.2 & 6.3 & 273 & 26 & 109 & 174 & 084 & $\mathrm{TF}$ \\
\hline CM19961123-01:59:52 & 076.84 & 39.00 & 33.0 & 5.0 & 345 & 19 & 117 & 062 & 152 & $\mathrm{TF}$ \\
\hline CM19970121-01:48:29 & 077.26 & 39.51 & 33.0 & 5.9 & 315 & 75 & -177 & 180 & 090 & SS \\
\hline CM19970129-08:20:18 & 077.42 & 38.97 & 33.0 & 5.2 & 042 & 43 & 010 & 173 & 083 & UF \\
\hline CM19970301-06:04:19 & 076.89 & 39.40 & 22.0 & 5.6 & 180 & 80 & -173 & 044 & 134 & SS \\
\hline CM19970405-23:46:23 & 076.93 & 39.41 & 33.0 & 5.9 & 161 & 78 & 179 & 026 & 116 & SS \\
\hline CM19970406-04:36:38 & 077.03 & 39.52 & 15.0 & 5.9 & 253 & 42 & -036 & 045 & 135 & NF \\
\hline CM19970406-12:58:21 & 076.99 & 39.48 & 33.0 & 5.3 & 227 & 36 & -061 & 037 & 127 & NF \\
\hline CM19970411-05:34:50 & 076.93 & 39.61 & 15.0 & 6.1 & 240 & 37 & -045 & 040 & 130 & NF \\
\hline CM19970412-21:09:15 & 077.20 & 39.64 & 16.0 & 5.3 & 243 & 48 & -065 & 046 & 136 & NF \\
\hline CM19970415-18:19:16 & 076.99 & 39.69 & 23.0 & 5.8 & 170 & 66 & -162 & 031 & 121 & SS \\
\hline CM19970624-09:24:51 & 077.18 & 39.80 & 33.8 & 5.1 & 345 & 72 & -167 & 029 & 119 & SS \\
\hline CM19971017-17:35:18 & 077.07 & 39.59 & 33.0 & 5.3 & 339 & 81 & 178 & 024 & 114 & SS \\
\hline CM19980319-13:51:39 & 076.88 & 39.94 & 32.7 & 5.6 & 243 & 23 & 079 & 156 & 066 & $\mathrm{TF}$ \\
\hline CM19980802-04:40:47 & 077.13 & 39.67 & 15.0 & 5.6 & 231 & 30 & -056 & 028 & 118 & NF \\
\hline CM19980827-09:03:41 & 077.22 & 39.51 & 32.0 & 6.3 & 240 & 78 & 000 & 015 & 105 & SS \\
\hline CM20030104-11:07:24 & 077.11 & 39.73 & 33.0 & 5.2 & 341 & 71 & -162 & 025 & 115 & SS \\
\hline CM20030224-02:03:54 & 077.24 & 39.37 & 24.0 & 6.3 & 239 & 33 & 062 & 164 & 074 & $\mathrm{TF}$ \\
\hline CM20030224-21:18:49 & 077.04 & 39.35 & 15.0 & 5.2 & 289 & 33 & 126 & 178 & 088 & $\mathrm{TF}$ \\
\hline CM20030225-03:52:48 & 077.62 & 39.52 & 15.0 & 5.3 & 110 & 77 & 166 & 157 & 067 & SS \\
\hline CM20030312-04:47:60 & 077.32 & 39.29 & 15.0 & 5.7 & 245 & 33 & 073 & 165 & 075 & $\mathrm{TF}$ \\
\hline CM20030315-22:59:32 & 077.47 & 39.74 & 15.0 & 5.0 & 330 & 57 & 178 & 016 & 106 & SS \\
\hline CM20030330-23:15:51 & 077.46 & 39.02 & 41.6 & 5.2 & 273 & 34 & 089 & 004 & 094 & $\mathrm{TF}$ \\
\hline CM20030504-15:44:36 & 077.39 & 38.86 & 15.0 & 5.8 & 308 & 53 & -179 & 178 & 088 & UF \\
\hline CM20030604-16:28:47 & 077.69 & 39.66 & 15.0 & 5.2 & 090 & 36 & 087 & 003 & 093 & $\mathrm{TF}$ \\
\hline
\end{tabular}


Table A1. (Continued.)

\begin{tabular}{|c|c|c|c|c|c|c|c|c|c|c|}
\hline \multirow[b]{2}{*}{ Data-time group event } & \multicolumn{3}{|c|}{ Location } & \multicolumn{4}{|c|}{ Focal mechanism data } & \multicolumn{2}{|c|}{$\mathrm{SH}$} & \multirow{2}{*}{$\begin{array}{l}\text { Stress } \\
\text { regime }\end{array}$} \\
\hline & Longitude & Latitude & Depth & $\overline{\mathrm{Mw}}$ & Strike & Dip & Slip & $\overline{\operatorname{Max}}$ & Min & \\
\hline Western Kaxgar region (Box- 7 ) & 17 & & & & & & & & & \\
\hline CM19770729-09:14:17 & 075.45 & 38.54 & 131.7 & 5.2 & 158 & 05 & 021 & 103 & 013 & UF \\
\hline CM19781008-14:20:08 & 074.29 & 39.48 & 10.0 & 5.9 & 246 & 36 & 027 & 006 & 096 & UF \\
\hline CM19800731-19:03:09 & 074.31 & 39.41 & 10.0 & 5.2 & 261 & 37 & 082 & 174 & 084 & $\mathrm{TF}$ \\
\hline CM19830213-01:40:17 & 075.11 & 39.94 & 15.0 & 6.2 & 230 & 60 & -007 & 161 & 071 & $\mathrm{NF}$ \\
\hline CM19830825-11:05:34 & 073.87 & 39.09 & 15.0 & 5.1 & 212 & 52 & 005 & 160 & 070 & UF \\
\hline CM19850823-12:42:13 & 075.09 & 39.54 & 15.4 & 6.9 & 315 & 29 & 159 & 022 & 112 & UF \\
\hline CM19850829-23:39:55 & 075.14 & 39.25 & 10.0 & 5.2 & 081 & 27 & 057 & 007 & 097 & $\mathrm{TF}$ \\
\hline CM19850911-20:45:01 & 075.32 & 39.50 & 10.0 & 6.1 & 090 & 44 & 068 & 016 & 106 & $\mathrm{TF}$ \\
\hline CM19870430-05:17:43 & 074.67 & 39.67 & 15.0 & 5.6 & 113 & 44 & 086 & 026 & 116 & $\mathrm{TF}$ \\
\hline CM19870608-13:30:36 & 075.30 & 39.64 & 15.0 & 5.1 & 298 & 27 & 091 & 029 & 119 & $\mathrm{TF}$ \\
\hline CM19880106-15:31:16 & 075.50 & 39.01 & 36.7 & 5.3 & 248 & 30 & 069 & 169 & 079 & $\mathrm{TF}$ \\
\hline CM19880923-04:46:44 & 074.47 & 39.66 & 15.0 & 5.1 & 106 & 23 & 064 & 030 & 120 & $\mathrm{TF}$ \\
\hline CM19900417-01:59:35 & 074.78 & 39.29 & 15.0 & 6.0 & 118 & 68 & 156 & 167 & 077 & SS \\
\hline CM20021525-12:57:03 & 074.90 & 38.95 & 15.0 & 5.6 & 325 & 36 & 160 & 020 & 110 & UF \\
\hline CM20030901-23:16:41 & 075.32 & 38.71 & 15.0 & 5.7 & 107 & 47 & -153 & 142 & 052 & NS \\
\hline CM20061224-02:58:34 & 074.56 & 39.83 & 17.3 & 5.0 & 299 & 51 & 130 & 001 & 091 & $\mathrm{TF}$ \\
\hline CM20080410-07:17:21 & 075.05 & 39.48 & 12.7 & 5.0 & 302 & 45 & 119 & 013 & 103 & $\mathrm{TF}$ \\
\hline
\end{tabular}

Hotan region (Box-8)

CM19951224-09:36:12

CM19970530-17:54:54

CM19980528-21:11:44

CM19990417-07:20:55

CM20050825-21:08:18

$$
5
$$

$\begin{array}{llrlllllll}078.16 & 37.72 & 33.0 & 5.1 & 138 & 23 & 114 & 036 & 126 & \text { TF } \\ 078.06 & 37.18 & 33.0 & 5.0 & 117 & 23 & 091 & 026 & 116 & \text { TF } \\ 079.06 & 37.55 & 29.3 & 5.6 & 095 & 09 & 063 & 018 & 108 & \text { UF } \\ 075.45 & 37.61 & 149.6 & 5.1 & 232 & 55 & 151 & 113 & 023 & \text { TF } \\ 079.35 & 37.13 & 15.0 & 5.4 & 089 & 23 & 068 & 012 & 102 & \text { TF }\end{array}$

Gansu region (Box-9)

CM19800601-06:19:02

CM19860826-09:43:07

CM19901020-08:07:33

CM19950721-22:44:10

CM19960601-12:49:17

CM19961120-18:09:22

CM20000606-10:59:13

CM20021214-13:27:35

CM20031025-12:41:42

CM20031025-12:48:03

CM20040504-05:05:00

CM20070722-09:34:34

CM20080330-08:32:28

CM20091002-13:49:11

Sichuan region (Box-10a)

CM19810123-21:13:56

CM19820615-23:24:38

CM19890118-18:22:54

CM19890415-20:34:21

CM19890425-02:13:31

CM19890503-05:53:12

CM19890503-15:41:41

\section{4}

$\begin{array}{rrrrrrrrrr}095.90 & 38.98 & 15.0 & 5.4 & 334 & 34 & 093 & 058 & 148 & \text { TF } \\ 101.72 & 37.80 & 15.0 & 5.9 & 125 & 37 & 055 & 056 & 146 & \text { TF } \\ 103.54 & 37.06 & 15.0 & 5.7 & 098 & 85 & -003 & 053 & 143 & \text { SS } \\ 103.03 & 36.26 & 15.0 & 5.6 & 104 & 41 & 091 & 012 & 102 & \text { TF } \\ 102.80 & 37.36 & 15.0 & 5.2 & 278 & 79 & -011 & 054 & 144 & \text { SS } \\ 096.23 & 40.23 & 15.0 & 5.7 & 101 & 46 & 059 & 033 & 123 & \text { TF } \\ 103.91 & 37.02 & 15.0 & 5.5 & 096 & 68 & -006 & 052 & 142 & \text { SS } \\ 097.23 & 39.85 & 15.0 & 5.5 & 098 & 34 & 097 & 005 & 095 & \text { TF } \\ 101.02 & 38.30 & 15.0 & 5.8 & 108 & 40 & 055 & 039 & 129 & \text { TF } \\ 100.84 & 38.15 & 15.0 & 5.8 & 085 & 54 & 021 & 034 & 124 & \text { SS } \\ 096.65 & 37.60 & 18.6 & 5.3 & 145 & 83 & 175 & 011 & 101 & \text { SS } \\ 101.37 & 38.42 & 24.1 & 5.0 & 159 & 85 & 176 & 024 & 114 & \text { SS } \\ 101.94 & 37.91 & 18.8 & 5.1 & 064 & 75 & 001 & 018 & 108 & \text { SS } \\ 096.12 & 39.62 & 20.3 & 5.0 & 194 & 82 & 180 & 058 & 148 & \text { SS }\end{array}$

10

\begin{tabular}{llllllllll}
101.35 & 30.86 & 10.0 & 6.5 & 319 & 73 & -004 & 095 & 005 & SS \\
100.55 & 31.90 & 10.0 & 5.6 & 105 & 72 & -003 & 061 & 151 & SS \\
100.13 & 29.88 & 15.0 & 5.2 & 120 & 50 & -020 & 082 & 172 & SS \\
099.37 & 29.92 & 15.0 & 6.4 & 273 & 29 & -073 & 085 & 175 & NF \\
099.41 & 29.90 & 15.0 & 6.1 & 245 & 40 & -114 & 079 & 169 & NF \\
099.69 & 30.00 & 15.0 & 6.2 & 240 & 44 & -117 & 078 & 168 & NF \\
099.43 & 29.83 & 15.0 & 5.8 & 271 & 45 & -090 & 091 & 001 & NF \\
\hline
\end{tabular}


Table A1. (Continued.)

\begin{tabular}{|c|c|c|c|c|c|c|c|c|c|c|}
\hline \multirow[b]{2}{*}{ Data-time group event } & \multicolumn{3}{|c|}{ Location } & \multicolumn{4}{|c|}{ Focal mechanism data } & \multicolumn{2}{|c|}{$\mathrm{SH}$} & \multirow{2}{*}{$\begin{array}{l}\text { Stress } \\
\text { regime }\end{array}$} \\
\hline & Longitude & Latitude & Depth & $\overline{\mathrm{Mw}}$ & Strike & Dip & Slip & $\operatorname{Max}$ & Min & \\
\hline CM19890721-03:09:23 & 099.54 & 29.79 & 15.0 & 5.6 & 059 & 38 & -127 & 082 & 172 & NF \\
\hline CM19961221-08:39:49 & 099.90 & 30.67 & 15.0 & 5.4 & 028 & 71 & -167 & 071 & 161 & $\mathrm{SS}$ \\
\hline CM20020808-11:42:11 & 099.95 & 30.69 & 55.1 & 5.3 & 092 & 41 & -086 & 089 & 179 & NF \\
\hline Sichuan region (Box-10b) & 30 & & & & & & & & & \\
\hline CM19760816-14:06:55 & 104.42 & 32.63 & 15.0 & 6.7 & 029 & 48 & 122 & 098 & 008 & $\mathrm{TF}$ \\
\hline CM19760821-21:49:58 & 104.29 & 32.37 & 15.3 & 6.3 & 198 & 40 & 113 & 072 & 162 & $\mathrm{TF}$ \\
\hline CM19760823-03:30:12 & 104.21 & 32.11 & 19.6 & 6.4 & 172 & 45 & 072 & 102 & 012 & $\mathrm{TF}$ \\
\hline CM19860806-19:55:20 & 101.20 & 29.15 & 15.0 & 5.3 & 040 & 41 & -162 & 078 & 168 & $\mathrm{UF}$ \\
\hline CM19890922-02:25:57 & 102.83 & 30.87 & 15.0 & 6.1 & 352 & 18 & 061 & 095 & 005 & $\mathrm{TF}$ \\
\hline CM20010223-00:09:28 & 101.32 & 29.44 & 33.0 & 5.6 & 092 & 34 & -073 & 080 & 170 & NF \\
\hline CM20080226-17:50:05 & 101.96 & 30.03 & 29.2 & 5.1 & 340 & 78 & -007 & 115 & 025 & SS \\
\hline CM20080512-06:28:40 & 104.10 & 31.44 & 12.8 & 7.9 & 231 & 35 & 138 & 139 & 049 & $\mathrm{TF}$ \\
\hline CM20080512-11:11:05 & 103.62 & 31.31 & 14.9 & 6.1 & 204 & 71 & -169 & 066 & 156 & SS \\
\hline CM20080512-20:08:53 & 104.11 & 31.37 & 28.4 & 5.6 & 227 & 41 & 132 & 129 & 039 & $\mathrm{TF}$ \\
\hline CM20080512-23:46:21 & 103.61 & 31.30 & 15.6 & 5.2 & 116 & 59 & -007 & 073 & 163 & SS \\
\hline CM20080512-23:54:49 & 103.58 & 31.30 & 20.7 & 5.1 & 063 & 37 & -099 & 068 & 158 & NF \\
\hline CM20080513-07:07:13 & 103.42 & 30.90 & 14.3 & 5.8 & 213 & 42 & 109 & 125 & 035 & $\mathrm{TF}$ \\
\hline CM20080514-02:54:40 & 103.59 & 31.28 & 12.0 & 5.4 & 215 & 80 & -177 & 079 & 169 & $\mathrm{SS}$ \\
\hline CM20080514-09:26:47 & 104.08 & 31.30 & 20.7 & 5.1 & 029 & 42 & 108 & 107 & 017 & $\mathrm{TF}$ \\
\hline CM20080516-05:25:51 & 103.33 & 31.25 & 24.0 & 5.6 & 235 & 71 & -170 & 098 & 008 & SS \\
\hline CM20080516-20:16:54 & 103.55 & 31.30 & 17.9 & 5.0 & 360 & 69 & 174 & 046 & 136 & SS \\
\hline CM20080517-17:08:30 & 105.08 & 32.21 & 16.1 & 5.8 & 038 & 45 & 077 & 137 & 047 & TF \\
\hline CM20080519-06:06:56 & 105.38 & 32.56 & 16.2 & 5.2 & 316 & 60 & 028 & 086 & 176 & $\mathrm{TF}$ \\
\hline CM20080525-08:21:52 & 105.45 & 32.57 & 27.0 & 6.1 & 059 & 84 & 178 & 103 & 013 & SS \\
\hline CM20080527-08:03:24 & 105.65 & 32.71 & 25.5 & 5.2 & 335 & 73 & 002 & 110 & 020 & SS \\
\hline CM20080527-08:37:54 & 105.66 & 32.74 & 24.1 & 5.5 & 089 & 73 & -164 & 132 & 042 & $\mathrm{SS}$ \\
\hline CM20080723-19:54:47 & 105.61 & 32.71 & 12.0 & 5.5 & 010 & 44 & 115 & 084 & 174 & $\mathrm{TF}$ \\
\hline CM20080724-07:09:32 & 105.55 & 32.82 & 13.4 & 5.6 & 110 & 75 & 012 & 063 & 153 & $\mathrm{SS}$ \\
\hline CM20080801-08:32:48 & 104.72 & 32.04 & 21.0 & 5.7 & 354 & 29 & 054 & 107 & 017 & $\mathrm{TF}$ \\
\hline CM20080805-09:49:20 & 105.57 & 32.69 & 12.0 & 6.0 & 348 & 44 & 103 & 068 & 158 & $\mathrm{TF}$ \\
\hline CM20080911-17:39:02 & 105.65 & 32.98 & 12.0 & 5.1 & 339 & 41 & 093 & 064 & 154 & $\mathrm{TF}$ \\
\hline CM20081115-22:59:52 & 104.74 & 32.14 & 29.2 & 5.0 & 077 & 83 & 003 & 032 & 122 & SS \\
\hline CM20081209-18:53:10 & 105.65 & 32.66 & 15.7 & 5.1 & 024 & 38 & 034 & 144 & 054 & $\mathrm{TF}$ \\
\hline CM20090629-18:03:55 & 104.15 & 31.31 & 12.0 & 5.3 & 212 & 29 & 054 & 142 & 052 & TF \\
\hline Northwestern Yunnan region (Box-11) & 15 & & & & & & & & & \\
\hline CM19761106-18:04:16 & 101.40 & 27.50 & 22.7 & 6.3 & 019 & 66 & -006 & 155 & 065 & SS \\
\hline CM19780831-03:26:54 & 101.04 & 27.41 & 10.0 & 5.3 & 005 & 58 & -026 & 147 & 057 & SS \\
\hline CM19800202-12:29:20 & 101.38 & 27.60 & 10.0 & 5.5 & 213 & 74 & -006 & 168 & 078 & NF \\
\hline CM19820703-08:13:38 & 100.27 & 26.59 & 10.0 & 5.3 & 347 & 26 & -090 & 173 & 083 & $\mathrm{NF}$ \\
\hline CM19930717-09:46:39 & 099.82 & 27.42 & 15.0 & 5.4 & 140 & 33 & -055 & 120 & 030 & $\mathrm{NF}$ \\
\hline CM19960203-11:14:32 & 100.28 & 27.15 & 15.0 & 6.6 & 000 & 36 & -068 & 164 & 074 & $\mathrm{NF}$ \\
\hline CM19960204-16:58:14 & 100.38 & 26.84 & 15.0 & 5.5 & 358 & 33 & -086 & 007 & 097 & $\mathrm{NF}$ \\
\hline CM19960206-07:36:22 & 100.12 & 27.52 & 15.0 & 5.4 & 132 & 57 & -141 & 164 & 074 & NS \\
\hline CM19960924-19:24:55 & 100.70 & 27.18 & 15.0 & 5.5 & 321 & 41 & -098 & 145 & 055 & $\mathrm{NF}$ \\
\hline CM19971023-12:28:38 & 100.55 & 27.14 & 15.0 & 5.1 & 153 & 20 & -110 & 162 & 072 & $\mathrm{NF}$ \\
\hline CM19981002-12:49:38 & 101.52 & 27.45 & 15.0 & 5.3 & 332 & 16 & -089 & 154 & 064 & $\mathrm{NF}$ \\
\hline CM19981119-11:38:18 & 101.47 & 27.25 & 15.0 & 5.6 & 031 & 79 & -009 & 168 & 078 & SS \\
\hline CM20010523-21:10:46 & 101.11 & 27.53 & 33.0 & 5.4 & 008 & 87 & -002 & 143 & 053 & SS \\
\hline CM20011027-05:35:46 & 101.01 & 26.36 & 15.0 & 5.5 & 035 & 69 & 001 & 170 & 080 & SS \\
\hline CM20030721-15:16:38 & 101.32 & 25.98 & 15.0 & 5.9 & 200 & 80 & -006 & 156 & 066 & SS \\
\hline
\end{tabular}


Table A1. (Continued.)

\begin{tabular}{|c|c|c|c|c|c|c|c|c|c|c|}
\hline \multirow[b]{2}{*}{ Data-time group event } & \multicolumn{3}{|c|}{ Location } & \multicolumn{4}{|c|}{ Focal mechanism data } & \multicolumn{2}{|c|}{$\mathrm{SH}$} & \multirow{2}{*}{$\begin{array}{l}\text { Stress } \\
\text { regime }\end{array}$} \\
\hline & Longitude & Latitude & Depth & $\overline{\mathrm{Mw}}$ & Strike & Dip & Slip & $\overline{\operatorname{Max}}$ & Min & \\
\hline Northern Yunnan region (Box-12) & 13 & & & & & & & & & \\
\hline CM19850418-05:52:56 & 102.64 & 25.39 & 10.0 & 5.7 & 100 & 57 & -170 & 142 & 052 & SS \\
\hline CM19860313-08:41:22 & 101.02 & 25.45 & 15.0 & 5.3 & 330 & 25 & -104 & 165 & 075 & $\mathrm{NF}$ \\
\hline CM19930814-14:30:08 & 101.80 & 25.63 & 33.0 & 5.2 & 209 & 76 & 015 & 162 & 072 & SS \\
\hline CM19951023-22:46:58 & 102.54 & 25.87 & 15.0 & 6.2 & 013 & 75 & -009 & 148 & 058 & SS \\
\hline CM20000114-22:09:06 & 101.28 & 25.34 & 33.0 & 5.5 & 025 & 77 & -002 & 160 & 070 & SS \\
\hline CM20000114-23:37:11 & 101.40 & 25.39 & 33.0 & 5.9 & 027 & 78 & -006 & 162 & 072 & $\mathrm{SS}$ \\
\hline CM20010709-23:51:35 & 101.25 & 24.89 & 33.0 & 5.1 & 233 & 50 & 002 & 000 & 090 & UF \\
\hline CM20031016-12:28:12 & 101.52 & 25.89 & 33.0 & 5.6 & 018 & 88 & -001 & 153 & 063 & SS \\
\hline CM20050805-14:14:47 & 103.19 & 26.46 & 27.0 & 5.2 & 252 & 73 & -178 & 118 & 028 & SS \\
\hline CM20080830-08:30:57 & 102.04 & 26.19 & 24.1 & 6.0 & 100 & 86 & 180 & 145 & 055 & SS \\
\hline CM20080831-08:31:14 & 102.01 & 26.16 & 24.6 & 5.6 & 011 & 77 & -007 & 146 & 056 & $\mathrm{SS}$ \\
\hline CM20090709-11:19:20 & 101.17 & 25.52 & 15.1 & 5.7 & 204 & 84 & -003 & 160 & 070 & $\mathrm{SS}$ \\
\hline CM20090710-09:02:04 & 101.10 & 25.54 & 14.9 & 5.2 & 021 & 83 & 004 & 156 & 066 & SS \\
\hline Southwestern Yunnan region (Box-13) & 19 & & & & & & & & & \\
\hline CM19760529-12:23:30 & 098.65 & 24.39 & 15.0 & 6.7 & 323 & 80 & -172 & 007 & 097 & SS \\
\hline CM19760529-14:00:33 & 098.58 & 24.29 & 15.0 & 6.6 & 242 & 88 & 000 & 018 & 108 & SS \\
\hline CM19760531-05:08:35 & 098.60 & 24.26 & 15.0 & 6.1 & 342 & 72 & -169 & 027 & 117 & SS \\
\hline CM19760721-15:10:52 & 098.57 & 24.74 & 15.0 & 6.1 & 338 & 88 & -178 & 024 & 114 & SS \\
\hline CM19780909-23:11:15 & 101.03 & 23.20 & 10.0 & 5.3 & 223 & 69 & 007 & 176 & 086 & SS \\
\hline CM19790315-12:52:30 & 101.61 & 23.24 & 10.0 & 6.0 & 033 & 62 & -003 & 168 & 078 & SS \\
\hline CM19810814-06:09:40 & 098.51 & 25.61 & 10.0 & 5.2 & 153 & 46 & -141 & 003 & 093 & NF \\
\hline CM19810919-06:51:02 & 101.54 & 22.84 & 10.0 & 5.3 & 143 & 71 & -172 & 006 & 096 & $\mathrm{SS}$ \\
\hline CM19821008-13:34:59 & 099.61 & 25.69 & 10.0 & 5.2 & 146 & 22 & -112 & 158 & 068 & NF \\
\hline CM19850905-18:30:26 & 098.23 & 25.29 & 60.7 & 5.5 & 014 & 65 & 177 & 060 & 150 & SS \\
\hline CM19881106-13:03:31 & 099.68 & 23.00 & 15.0 & 7.0 & 333 & 78 & 174 & 019 & 109 & SS \\
\hline CM19881107-02:40:03 & 099.42 & 23.38 & 15.0 & 5.2 & 122 & 55 & 040 & 064 & 154 & $\mathrm{TS}$ \\
\hline CM19881127-04:17:59 & 100.17 & 22.70 & 15.0 & 5.5 & 071 & 61 & 014 & 022 & 112 & SS \\
\hline CM19881130-08:13:29 & 099.54 & 22.15 & 15.0 & 6.0 & 167 & 75 & -177 & 032 & 122 & SS \\
\hline CM19890507-00:38:20 & 099.65 & 23.46 & 15.0 & 5.6 & 335 & 76 & 169 & 021 & 111 & SS \\
\hline CM19930126-20:32:09 & 100.88 & 22.86 & 24.4 & 5.6 & 050 & 82 & -005 & 006 & 096 & SS \\
\hline CM19950424-16:13:14 & 103.16 & 22.88 & 33.0 & 5.2 & 102 & 80 & -173 & 147 & 057 & SS \\
\hline CM20010412-10:47:09 & 098.81 & 24.77 & 15.0 & 5.6 & 057 & 63 & -028 & 019 & 109 & SS \\
\hline CM20070602-21:35:01 & 101.13 & 23.02 & 12.0 & 6.1 & 146 & 63 & 156 & 016 & 106 & SS \\
\hline Northwestern Qinghai region (Box-14) & 9 & & & & & & & & & \\
\hline CM19770101-21:39:46 & 090.67 & 38.22 & 10.0 & 6.0 & 322 & 37 & 127 & 030 & 120 & $\mathrm{TF}$ \\
\hline CM19790928-07:46:51 & 090.45 & 37.81 & 15.0 & 5.1 & 129 & 23 & 042 & 065 & 155 & $\mathrm{TF}$ \\
\hline CM19791202-01:37:16 & 090.09 & 38.55 & 12.0 & 5.5 & 255 & 67 & 020 & 025 & 115 & SS \\
\hline CM19870225-19:56:45 & 091.08 & 38.30 & 15.0 & 5.8 & 127 & 36 & 124 & 018 & 108 & $\mathrm{TF}$ \\
\hline CM19900114-03:03:31 & 092.10 & 37.60 & 15.0 & 6.0 & 072 & 45 & 041 & 012 & 102 & $\mathrm{TF}$ \\
\hline CM19931002-08:42:39 & 088.82 & 38.16 & 15.0 & 6.1 & 326 & 42 & 146 & 026 & 116 & $\mathrm{UF}$ \\
\hline CM19940907-13:56:24 & 090.19 & 38.42 & 33.0 & 5.2 & 238 & 58 & -006 & 021 & 111 & NF \\
\hline CM20000131-07:26:02 & 088.75 & 38.00 & 33.0 & 5.4 & 347 & 76 & 167 & 033 & 123 & SS \\
\hline CM20070202-22:32:24 & 091.85 & 37.87 & 20.2 & 5.4 & 111 & 45 & 114 & 004 & 094 & $\mathrm{TF}$ \\
\hline Central Qinghai region (Box-15) & 19 & & & & & & & & & \\
\hline CM19770119-00:46:22 & 094.81 & 37.08 & 10.0 & 5.8 & 289 & 35 & 068 & 032 & 122 & $\mathrm{TF}$ \\
\hline CM19850811-16:06:05 & 095.88 & 36.41 & 10.0 & 5.3 & 200 & 33 & 123 & 078 & 168 & $\mathrm{TF}$ \\
\hline CM19951218-04:57:12 & 097.63 & 34.74 & 33.0 & 5.7 & 046 & 81 & 176 & 091 & 001 & SS \\
\hline CM19970209-11:28:22 & 095.82 & 35.70 & 15.0 & 5.5 & 001 & 70 & -172 & 044 & 134 & SS \\
\hline CM20021026-20:28:51 & 096.14 & 35.18 & 33.0 & 5.3 & 011 & 78 & 176 & 057 & 147 & SS \\
\hline CM20030417-00:48:46 & 096.45 & 37.53 & 16.0 & 6.3 & 294 & 29 & 088 & 026 & 116 & $\mathrm{TF}$ \\
\hline
\end{tabular}


Table A1. (Continued.)

\begin{tabular}{|c|c|c|c|c|c|c|c|c|c|c|}
\hline \multirow[b]{2}{*}{ Data-time group event } & \multicolumn{3}{|c|}{ Location } & \multicolumn{4}{|c|}{ Focal mechanism data } & \multicolumn{2}{|c|}{$\mathrm{SH}$} & \multirow{2}{*}{$\begin{array}{l}\text { Stress } \\
\text { regime }\end{array}$} \\
\hline & $\overline{\text { Longitude }}$ & Latitude & $\overline{\text { Depth }}$ & $\overline{\mathrm{Mw}}$ & Strike & Dip & Slip & $\overline{\operatorname{Max}}$ & $\overline{\text { Min }}$ & \\
\hline CM20040224-20:21:52 & 096.61 & 37.66 & 23.0 & 5.0 & 141 & 87 & -179 & 006 & 096 & SS \\
\hline CM20040316-21:23:24 & 096.56 & 37.60 & 13.0 & 5.1 & 127 & 42 & 116 & 021 & 111 & $\mathrm{TF}$ \\
\hline CM20040504-11:36:05 & 096.62 & 37.61 & 21.6 & 5.2 & 140 & 87 & -178 & 005 & 095 & SS \\
\hline CM20040510-23:27:30 & 096.58 & 37.55 & 12.0 & 5.5 & 272 & 33 & 069 & 015 & 105 & $\mathrm{TF}$ \\
\hline CM20060329-23:38:55 & 095.62 & 35.53 & 24.3 & 5.3 & 297 & 73 & 011 & 072 & 162 & $\mathrm{TF}$ \\
\hline CM20081110-01:22:10 & 095.75 & 37.51 & 27.2 & 6.3 & 252 & 28 & 057 & 010 & 100 & $\mathrm{TF}$ \\
\hline CM20081111-21:56:05 & 095.82 & 37.52 & 23.9 & 5.1 & 357 & 41 & 158 & 050 & 140 & $\mathrm{UF}$ \\
\hline CM20090828-01:52:13 & 095.76 & 37.64 & 12.0 & 6.3 & 295 & 31 & 102 & 018 & 108 & $\mathrm{TF}$ \\
\hline CM20090828-16:28:44 & 095.76 & 37.75 & 17.0 & 5.0 & 056 & 80 & -003 & 012 & 102 & SS \\
\hline CM20090830-17:15:53 & 095.57 & 37.66 & 16.8 & 5.4 & 272 & 45 & 118 & 164 & 074 & $\mathrm{TF}$ \\
\hline CM20090831-10:15:34 & 095.86 & 37.59 & 12.0 & 5.8 & 277 & 33 & 090 & 007 & 097 & $\mathrm{TF}$ \\
\hline CM20091104-21:56:14 & 095.83 & 37.65 & 14.5 & 5.1 & 313 & 52 & 151 & 010 & 100 & $\mathrm{TS}$ \\
\hline CM20091221-05:15:14 & 096.68 & 37.57 & 22.1 & 5.0 & 122 & 43 & 112 & 017 & 107 & $\mathrm{TF}$ \\
\hline Eastern Qinghai region (Box-16) & 11 & & & & & & & & & \\
\hline CM19900426-09:37:23 & 100.27 & 36.01 & 15.0 & 6.2 & 090 & 40 & 019 & 038 & 128 & UF \\
\hline CM19900426-09:37:28 & 100.57 & 36.25 & 15.0 & 6.4 & 101 & 46 & 041 & 042 & 132 & $\mathrm{TF}$ \\
\hline CM19900507-05:17:44 & 100.74 & 35.30 & 15.0 & 5.3 & 156 & 37 & 122 & 047 & 137 & $\mathrm{TF}$ \\
\hline CM19900515-22:30:13 & 100.26 & 36.65 & 15.0 & 5.3 & 271 & 17 & 047 & 022 & 112 & $\mathrm{TF}$ \\
\hline CM19940103-05:52:36 & 100.51 & 35.71 & 15.0 & 5.7 & 156 & 35 & 123 & 047 & 137 & $\mathrm{TF}$ \\
\hline CM19940904-14:50:44 & 100.15 & 36.08 & 15.0 & 5.2 & 165 & 26 & 094 & 072 & 162 & $\mathrm{TF}$ \\
\hline CM19940923-19:15:51 & 100.05 & 36.07 & 15.0 & 5.3 & 123 & 31 & 071 & 044 & 134 & $\mathrm{TF}$ \\
\hline CM19941010-14:08:05 & 100.18 & 36.13 & 33.0 & 5.1 & 327 & 45 & 109 & 043 & 133 & $\mathrm{TF}$ \\
\hline CM19950709-15:56:29 & 100.35 & 35.55 & 33.0 & 5.1 & 100 & 33 & 077 & 017 & 107 & $\mathrm{TF}$ \\
\hline CM20000912-00:28:05 & 099.48 & 35.50 & 15.0 & 6.1 & 343 & 80 & -170 & 027 & 117 & SS \\
\hline CM20000920-19:21:18 & 099.61 & 35.32 & 15.0 & 5.0 & 354 & 59 & -177 & 038 & 128 & SS \\
\hline Southern Qinghai region (Box-17) & 8 & & & & & & & & & \\
\hline CM19790329-07:07:25 & 097.75 & 32.61 & 12.0 & 5.8 & 358 & 75 & -174 & 042 & 132 & SS \\
\hline CM20000415-09:32:39 & 095.65 & 32.85 & 33.0 & 5.2 & 090 & 68 & -004 & 046 & 136 & SS \\
\hline CM20000913-15:11:23 & 095.12 & 33.94 & 15.0 & 5.0 & 084 & 77 & 001 & 039 & 129 & SS \\
\hline CM20010725-16:02:58 & 095.85 & 33.27 & 33.0 & 5.5 & 350 & 53 & -164 & 033 & 123 & NF \\
\hline CM20020629-06:54:48 & 094.28 & 34.06 & 33.0 & 5.6 & 090 & 87 & 003 & 045 & 135 & SS \\
\hline CM20060717-20:41:56 & 096.40 & 33.07 & 22.1 & 5.2 & 297 & 70 & -001 & 074 & 164 & SS \\
\hline CM20060719-09:53:08 & 096.27 & 33.06 & 24.6 & 5.5 & 302 & 64 & 004 & 079 & 169 & $\mathrm{TF}$ \\
\hline CM20070507-11:59:53 & 097.95 & 31.44 & 14.5 & 5.5 & 210 & 73 & -173 & 073 & 163 & SS \\
\hline Southwestern Qinghai region (Box-18) & 20 & & & & & & & & & \\
\hline CM19800306-21:00:19 & 091.93 & 36.37 & 10.0 & 5.4 & 285 & 59 & 029 & 052 & 142 & TF \\
\hline CM19810609-22:08:27 & 091.28 & 34.21 & 10.0 & 6.0 & 076 & 81 & -003 & 031 & 121 & SS \\
\hline CM19860820-21:24:03 & 091.96 & 34.58 & 15.0 & 6.4 & 253 & 69 & -018 & 031 & 121 & SS \\
\hline CM19881105-02:14:40 & 091.70 & 34.17 & 15.0 & 6.2 & 158 & 67 & 171 & 026 & 116 & SS \\
\hline CM19881125-22:29:44 & 091.77 & 34.29 & 15.0 & 5.5 & 262 & 60 & 007 & 035 & 125 & SS \\
\hline CM19890513-23:19:48 & 091.65 & 35.69 & 15.0 & 5.3 & 248 & 66 & 002 & 022 & 112 & SS \\
\hline CM19941228-03:56:23 & 090.57 & 35.75 & 33.0 & 5.1 & 031 & 25 & -116 & 043 & 133 & NF \\
\hline CM20000212-00:04:29 & 090.88 & 34.05 & 33.0 & 5.1 & 257 & 79 & 006 & 032 & 122 & SS \\
\hline CM20011114-09:27:16 & 092.91 & 35.80 & 15.0 & 7.8 & 094 & 61 & -012 & 052 & 142 & SS \\
\hline CM20011118-21:59:60 & 093.51 & 35.94 & 15.0 & 5.6 & 282 & 40 & 112 & 178 & 088 & $\mathrm{TF}$ \\
\hline CM20011119-17:45:30 & 093.52 & 35.83 & 15.0 & 5.3 & 100 & 44 & 090 & 010 & 100 & $\mathrm{TF}$ \\
\hline CM20011130-10:43:22 & 091.11 & 36.07 & 15.0 & 5.2 & 187 & 34 & -149 & 040 & 130 & UF \\
\hline
\end{tabular}


Table A1. (Continued.)

\begin{tabular}{|c|c|c|c|c|c|c|c|c|c|c|}
\hline \multirow[b]{2}{*}{ Data-time group event } & \multicolumn{3}{|c|}{ Location } & \multicolumn{4}{|c|}{ Focal mechanism data } & \multicolumn{2}{|c|}{$\mathrm{SH}$} & \multirow{2}{*}{$\begin{array}{l}\text { Stress } \\
\text { regime }\end{array}$} \\
\hline & Longitude & Latitude & $\overline{\text { Depth }}$ & $\overline{\mathrm{Mw}}$ & Strike & Dip & Slip & $\overline{\operatorname{Max}}$ & Min & \\
\hline CM20011201-12:25:29 & 093.93 & 35.58 & 15.0 & 5.1 & 254 & 36 & -141 & 081 & 171 & NF \\
\hline CM20011208-04:12:56 & 093.13 & 36.07 & 15.0 & 5.2 & 089 & 30 & -040 & 062 & 152 & NF \\
\hline CM20021019-07:24:41 & 092.87 & 35.72 & 33.0 & 5.1 & 186 & 76 & -166 & 050 & 140 & SS \\
\hline CM20040629-08:11:32 & 092.54 & 35.75 & 17.1 & 5.3 & 093 & 63 & -015 & 051 & 141 & SS \\
\hline CM20041210-03:44:05 & 093.35 & 35.83 & 19.4 & 5.0 & 341 & 48 & 133 & 043 & 133 & $\mathrm{TF}$ \\
\hline CM20080618-05:23:35 & 091.33 & 35.31 & 22.5 & 5.4 & 252 & 88 & 000 & 027 & 117 & SS \\
\hline CM20080818-14:11:10 & 091.93 & 33.65 & 23.2 & 5.3 & 170 & 84 & -178 & 036 & 126 & SS \\
\hline CM20081020-14:26:35 & 091.32 & 35.26 & 22.9 & 5.0 & 341 & 86 & -177 & 026 & 116 & SS \\
\hline Eastern Tibet region (Box-19) & 20 & & & & & & & & & \\
\hline CM19900602-00:32:43 & 093.28 & 32.20 & 15.0 & 5.2 & 043 & 44 & -044 & 016 & 106 & NF \\
\hline CM19940629-18:22:45 & 093.68 & 32.57 & 15.0 & 5.9 & 009 & 40 & -105 & 023 & 113 & NF \\
\hline CM19940630-00:48:38 & 093.76 & 32.53 & 15.0 & 5.0 & 346 & 38 & -118 & 019 & 109 & NF \\
\hline CM19990529-20:10:51 & 093.77 & 32.81 & 33.0 & 5.3 & 261 & 80 & -003 & 037 & 127 & $\mathrm{SS}$ \\
\hline CM20000105-09:45:30 & 092.29 & 32.03 & 33.0 & 5.4 & 225 & 36 & -020 & 178 & 088 & UF \\
\hline CM20000710-04:25:23 & 092.55 & 32.74 & 15.0 & 5.3 & 006 & 38 & -113 & 026 & 116 & NF \\
\hline CM20030211-10:36:31 & 093.67 & 32.55 & 46.1 & 5.1 & 017 & 35 & -062 & 000 & 090 & NF \\
\hline CM20030520-18:34:44 & 093.23 & 32.53 & 33.0 & 5.1 & 040 & 31 & -038 & 012 & 102 & $\mathrm{NF}$ \\
\hline CM20030524-11:28:02 & 092.29 & 32.16 & 33.0 & 5.0 & 349 & 17 & -080 & 164 & 074 & NF \\
\hline CM20030524-19:32:43 & 092.36 & 32.59 & 33.0 & 5.0 & 352 & 28 & -103 & 006 & 096 & $\mathrm{NF}$ \\
\hline CM20040824-10:05:40 & 092.28 & 32.50 & 12.0 & 5.5 & 052 & 49 & -030 & 018 & 108 & NS \\
\hline CM20020927-17:14:44 & 093.49 & 32.95 & 33.0 & 5.1 & 172 & 81 & -171 & 037 & 127 & SS \\
\hline CM20040306-11:54:44 & 092.13 & 33.26 & 12.0 & 5.0 & 195 & 46 & -131 & 040 & 130 & NF \\
\hline CM20080608-17:56:24 & 092.19 & 33.08 & 18.5 & 5.2 & 154 & 63 & -155 & 014 & 104 & $\mathrm{SS}$ \\
\hline CM20080610-10:05:04 & 092.25 & 33.13 & 16.5 & 5.4 & 160 & 57 & -146 & 015 & 105 & NS \\
\hline CM20080610-11:04:18 & 092.22 & 33.04 & 14.3 & 5.1 & 168 & 49 & -142 & 019 & 109 & $\mathrm{NF}$ \\
\hline CM20080610-14:15:44 & 092.22 & 33.07 & 13.0 & 5.3 & 170 & 47 & -131 & 016 & 106 & NF \\
\hline CM20080618-08:12:18 & 092.21 & 33.09 & 18.7 & 5.2 & 154 & 62 & -156 & 013 & 103 & $\mathrm{SS}$ \\
\hline CM20080716-22:58:24 & 092.24 & 33.15 & 16.6 & 5.3 & 159 & 68 & -160 & 020 & 110 & SS \\
\hline CM20080805-21:59:50 & 092.22 & 33.13 & 15.3 & 5.0 & 049 & 60 & -027 & 011 & 101 & SS \\
\hline
\end{tabular}

Southern Tibet region (Box-20a) 11

CM19820122-04:30:05

CM19870925-23:16:34

CM19890203-17:50:10

CM19890409-02:31:43

CM19920730-08:25:00

CM19930118-12:42:13

CM20040307-13:29:49

CM20060419-21:05:44

CM20081006-08:30:52

CM20081006-12:10:38

CM20081008-14:07:22

$\begin{array}{llllllllll}089.75 & 30.87 & 10.0 & 5.5 & 139 & 36 & -132 & 163 & 073 & \mathrm{NF} \\ 090.34 & 29.47 & 15.0 & 5.0 & 201 & 45 & -090 & 022 & 112 & \mathrm{NF} \\ 090.13 & 29.74 & 15.0 & 5.4 & 221 & 77 & -009 & 176 & 086 & \mathrm{SS} \\ 089.94 & 28.74 & 15.0 & 5.1 & 330 & 43 & -119 & 157 & 067 & \mathrm{NF} \\ 090.30 & 29.46 & 15.0 & 6.1 & 010 & 42 & -094 & 022 & 112 & \mathrm{NF} \\ 090.28 & 30.34 & 15.0 & 5.9 & 025 & 48 & -057 & 002 & 092 & \mathrm{NF} \\ 091.33 & 31.60 & 20.7 & 5.6 & 326 & 80 & -173 & 011 & 101 & \mathrm{SS} \\ 090.67 & 31.61 & 23.2 & 5.7 & 325 & 80 & -179 & 010 & 100 & \mathrm{SS} \\ 090.50 & 29.66 & 12.0 & 6.3 & 044 & 48 & -055 & 022 & 112 & \mathrm{NF} \\ 090.53 & 29.56 & 13.6 & 5.2 & 173 & 43 & -121 & 014 & 104 & \mathrm{NF} \\ 090.57 & 29.76 & 14.7 & 5.5 & 069 & 62 & -025 & 030 & 120 & \mathrm{SS}\end{array}$

Southern Tibet region (Box-20b) 19

CM19800222-03:02:58

CM19860110-03:46:44

CM19860620-17:12:52

CM19860719-20:12:59

CM19930320-14:52:11

CM19930320-21:26:49

CM19940723-20:58:10

\begin{tabular}{llllllrlll}
089.16 & 30.69 & 10.0 & 6.3 & 007 & 39 & -084 & 012 & 102 & NF \\
087.09 & 28.60 & 81.4 & 5.1 & 140 & 46 & -163 & 178 & 088 & UF \\
086.77 & 30.82 & 15.0 & 6.0 & 051 & 78 & -004 & 006 & 096 & SS \\
086.88 & 30.88 & 15.0 & 5.1 & 051 & 78 & 004 & 006 & 096 & SS \\
087.64 & 28.87 & 15.0 & 6.2 & 161 & 46 & 121 & 049 & 139 & TF \\
087.35 & 29.03 & 26.6 & 5.1 & 160 & 16 & -106 & 169 & 079 & NF \\
086.51 & 31.04 & 17.0 & 5.4 & 142 & 67 & 171 & 010 & 100 & SS \\
\hline
\end{tabular}


Table A1. (Continued.)

\begin{tabular}{|c|c|c|c|c|c|c|c|c|c|c|}
\hline \multirow[b]{2}{*}{ Data-time group event } & \multicolumn{3}{|c|}{ Location } & \multicolumn{4}{|c|}{ Focal mechanism data } & \multicolumn{2}{|c|}{$\mathrm{SH}$} & \multirow{2}{*}{$\begin{array}{l}\text { Stress } \\
\text { regime }\end{array}$} \\
\hline & Longitude & Latitude & $\overline{\text { Depth }}$ & $\overline{\mathrm{Mw}}$ & Strike & Dip & Slip & $\overline{\operatorname{Max}}$ & $\overline{\text { Min }}$ & \\
\hline CM19960703-06:44:52 & 088.32 & 29.77 & 15.0 & 5.6 & 172 & 45 & -102 & 015 & 105 & $\mathrm{NF}$ \\
\hline CM19960703-10:10:42 & 088.19 & 29.92 & 33.0 & 5.0 & 175 & 27 & -083 & 170 & 080 & NF \\
\hline CM19960731-08:00:34 & 088.67 & 29.74 & 15.0 & 5.4 & 023 & 32 & -041 & 176 & 086 & NF \\
\hline CM19971103-02:29:57 & 085.39 & 28.60 & 33.0 & 5.5 & 021 & 31 & -070 & 009 & 099 & $\mathrm{NF}$ \\
\hline CM19980720-01:06:07 & 088.47 & 29.83 & 15.0 & 5.7 & 016 & 32 & -083 & 012 & 102 & $\mathrm{NF}$ \\
\hline CM19980721-14:40:54 & 088.50 & 29.93 & 15.7 & 5.0 & 034 & 43 & -090 & 033 & 123 & $\mathrm{NF}$ \\
\hline CM19980825-07:41:53 & 088.31 & 29.86 & 15.0 & 5.8 & 014 & 46 & -067 & 008 & 098 & NF \\
\hline CM19980828-22:02:02 & 088.41 & 30.08 & 15.0 & 5.0 & 199 & 45 & -090 & 023 & 113 & NF \\
\hline CM19980930-02:29:59 & 088.25 & 29.64 & 33.0 & 5.1 & 139 & 32 & -112 & 152 & 062 & NF \\
\hline CM19981005-10:24:57 & 088.60 & 29.89 & 33.0 & 5.2 & 026 & 29 & -077 & 019 & 109 & NF \\
\hline CM20090724-03:12:03 & 086.10 & 31.05 & 28.1 & 5.8 & 318 & 74 & -172 & 002 & 092 & SS \\
\hline CM20091107-20:08:54 & 086.28 & 29.31 & 18.8 & 5.5 & 178 & 43 & -092 & 161 & 071 & NF \\
\hline Southwestern Tibet region (Box-21) & 21 & & & & & & & & & \\
\hline CM19970321-21:04:58 & 085.02 & 33.15 & 15.0 & 5.3 & 035 & 26 & -043 & 011 & 101 & NF \\
\hline CM20040711-23:08:51 & 083.78 & 30.56 & 13.0 & 6.2 & 359 & 45 & -074 & 167 & 077 & NF \\
\hline CM20040728-22:22:16 & 083.63 & 30.35 & 13.7 & 5.0 & 009 & 47 & -064 & 170 & 080 & $\mathrm{NF}$ \\
\hline CM20050407-20:04:47 & 083.77 & 30.24 & 12.0 & 6.3 & 170 & 43 & -091 & 160 & 070 & NF \\
\hline CM20050407-21:41:42 & 083.72 & 30.54 & 19.1 & 5.4 & 189 & 34 & -054 & 161 & 071 & $\mathrm{NF}$ \\
\hline CM20050408-19:51:41 & 083.76 & 30.25 & 19.6 & 5.0 & 177 & 45 & -084 & 153 & 063 & $\mathrm{NF}$ \\
\hline CM20080109-08:26:53 & 085.32 & 32.30 & 13.3 & 6.4 & 206 & 46 & -075 & 030 & 120 & $\mathrm{NF}$ \\
\hline CM20080116-11:54:51 & 085.29 & 32.35 & 12.0 & 5.9 & 023 & 44 & -087 & 021 & 111 & $\mathrm{NF}$ \\
\hline CM20080122-18:43:38 & 085.22 & 32.31 & 12.6 & 5.5 & 045 & 35 & -060 & 027 & 117 & NF \\
\hline CM20080425-12:03:56 & 085.42 & 32.65 & 26.6 & 5.0 & 328 & 60 & -173 & 015 & 105 & NF \\
\hline CM20080608-18:24:49 & 085.32 & 32.40 & 20.6 & 5.1 & 354 & 41 & -114 & 023 & 113 & NF \\
\hline CM20080825-13:22:09 & 083.51 & 30.61 & 17.3 & 6.7 & 030 & 48 & -048 & 004 & 094 & NF \\
\hline CM20080825-19:13:57 & 083.48 & 30.41 & 19.2 & 5.1 & 158 & 41 & -114 & 172 & 082 & $\mathrm{NF}$ \\
\hline CM20080825-20:40:49 & 083.72 & 30.85 & 23.7 & 5.0 & 225 & 68 & -019 & 003 & 093 & $\mathrm{NF}$ \\
\hline CM20080830-21:31:17 & 083.67 & 30.73 & 22.2 & 5.0 & 209 & 74 & -015 & 166 & 076 & $\mathrm{NF}$ \\
\hline CM20080910-01:14:38 & 083.71 & 30.79 & 20.3 & 5.3 & 206 & 77 & -012 & 163 & 073 & $\mathrm{NF}$ \\
\hline CM20080910-01:28:12 & 083.64 & 30.69 & 19.6 & 5.4 & 317 & 68 & -163 & 179 & 089 & NF \\
\hline CM20080925-01:47:18 & 083.69 & 30.66 & 21.2 & 6.0 & 208 & 75 & -013 & 164 & 074 & $\mathrm{NF}$ \\
\hline CM20090218-10:11:43 & 083.95 & 30.43 & 20.0 & 5.1 & 206 & 68 & 003 & 158 & 068 & SS \\
\hline CM20090929-06:01:19 & 083.55 & 30.56 & 21.1 & 5.0 & 036 & 56 & -031 & 000 & 090 & NS \\
\hline CM20091120-07:17:02 & 083.71 & 30.60 & 18.9 & 5.0 & 115 & 46 & -136 & 143 & 053 & $\mathrm{NF}$ \\
\hline Western Tibet region (Box-22) & 24 & & & & & & & & & \\
\hline CM19780404-00:40:35 & 082.03 & 33.03 & 10.0 & 5.9 & 223 & 59 & -008 & 176 & 086 & NF \\
\hline CM19780731-11:55:46 & 081.78 & 35.68 & 10.0 & 5.5 & 219 & 28 & -032 & 020 & 110 & $\mathrm{NF}$ \\
\hline CM19801007-09:32:16 & 082.06 & 35.76 & 15.0 & 5.8 & 192 & 39 & -053 & 160 & 070 & NF \\
\hline CM19820123-17:37:37 & 082.24 & 31.71 & 10.0 & 6.3 & 017 & 38 & -058 & 178 & 088 & $\mathrm{NF}$ \\
\hline CM19821031-18:40:58 & 082.36 & 36.07 & 10.0 & 5.4 & 215 & 45 & -015 & 172 & 082 & $\mathrm{UF}$ \\
\hline CM19850615-15:17:47 & 083.37 & 34.55 & 10.0 & 5.3 & 040 & 61 & -030 & 003 & 093 & NS \\
\hline CM19860706-19:24:30 & 080.15 & 34.24 & 15.0 & 5.9 & 263 & 74 & -015 & 040 & 130 & SS \\
\hline CM19920627-13:21:27 & 081.12 & 35.18 & 33.0 & 5.0 & 012 & 30 & -090 & 011 & 101 & $\mathrm{NF}$ \\
\hline CM20020604-14:36:09 & 081.25 & 30.13 & 15.0 & 5.6 & 159 & 49 & -130 & 005 & 095 & $\mathrm{NF}$ \\
\hline CM20041026-02:11:37 & 080.97 & 30.88 & 12.0 & 5.6 & 112 & 73 & -165 & 156 & 066 & SS \\
\hline CM20070505-08:51:48 & 081.97 & 34.33 & 23.9 & 6.1 & 220 & 88 & 002 & 175 & 085 & SS \\
\hline CM20071230-09:55:31 & 084.51 & 36.44 & 24.4 & 5.0 & 236 & 64 & 000 & 012 & 102 & SS \\
\hline CM20080320-22:33:12 & 081.37 & 35.43 & 12.0 & 7.1 & 358 & 41 & -110 & 024 & 114 & $\mathrm{NF}$ \\
\hline
\end{tabular}


Table A1. (Continued.)

\begin{tabular}{|c|c|c|c|c|c|c|c|c|c|c|}
\hline \multirow[b]{2}{*}{ Data-time group event } & \multicolumn{3}{|c|}{ Location } & \multicolumn{4}{|c|}{ Focal mechanism data } & \multicolumn{2}{|c|}{$\mathrm{SH}$} & \multirow{2}{*}{$\begin{array}{l}\text { Stress } \\
\text { regime }\end{array}$} \\
\hline & Longitude & Latitude & $\overline{\text { Depth }}$ & $\overline{\mathrm{Mw}}$ & Strike & Dip & Slip & $\overline{\operatorname{Max}}$ & $\overline{\text { Min }}$ & \\
\hline CM20080321-06:16:08 & 081.65 & 35.89 & 29.9 & 5.2 & 199 & 40 & -062 & 024 & 114 & NF \\
\hline CM20080321-12:03:00 & 081.43 & 35.39 & 19.5 & 5.2 & 200 & 40 & -073 & 037 & 127 & NF \\
\hline CM20080321-20:52:18 & 081.16 & 35.09 & 27.8 & 5.0 & 222 & 56 & -021 & 174 & 084 & $\mathrm{NF}$ \\
\hline CM20080323-20:56:19 & 081.65 & 35.86 & 16.1 & 5.1 & 206 & 47 & -046 & 167 & 077 & NF \\
\hline CM20080324-07:58:37 & 081.64 & 35.80 & 27.5 & 5.1 & 224 & 67 & 007 & 177 & 087 & SS \\
\hline CM20080326-10:39:32 & 081.66 & 35.85 & 17.7 & 5.2 & 141 & 80 & 172 & 007 & 097 & SS \\
\hline CM20080418-03:01:56 & 081.29 & 35.28 & 35.3 & 5.0 & 128 & 73 & 177 & 173 & 083 & SS \\
\hline CM20090401-02:34:42 & 082.47 & 33.73 & 20.9 & 5.0 & 342 & 46 & -119 & 177 & 087 & NF \\
\hline CM20090604-02:54:55 & 081.82 & 32.79 & 26.6 & 5.0 & 211 & 70 & -013 & 167 & 077 & NF \\
\hline CM20090809-04:02:11 & 081.58 & 35.76 & 18.3 & 5.1 & 226 & 43 & -008 & 004 & 094 & UF \\
\hline CM20091025-11:40:52 & 080.25 & 34.94 & 17.6 & 5.0 & 353 & 62 & 178 & 038 & 128 & $\mathrm{SS}$ \\
\hline Northeastern Tibet region (Box-23) & 29 & & & & & & & & & \\
\hline CM19771118-05:20:18 & 088.14 & 33.00 & 10.0 & 6.4 & 191 & 19 & -088 & 011 & 101 & $\mathrm{NF}$ \\
\hline CM19800624-07:35:58 & 088.77 & 33.09 & 15.0 & 5.7 & 156 & 73 & -165 & 019 & 109 & SS \\
\hline CM19831105-19:48:31 & 090.06 & 33.97 & 10.0 & 5.6 & 250 & 73 & -007 & 026 & 116 & SS \\
\hline CM19850421-13:21:33 & 087.18 & 35.72 & 10.0 & 5.6 & 246 & 50 & 000 & 037 & 127 & UF \\
\hline CM19850520-15:11:47 & 087.16 & 35.58 & 10.0 & 5.8 & 156 & 79 & 175 & 021 & 111 & SS \\
\hline CM19921222-16:42:44 & 088.03 & 34.67 & 15.0 & 5.2 & 152 & 41 & -139 & 000 & 090 & $\mathrm{NF}$ \\
\hline CM19940814-07:38:35 & 089.18 & 34.97 & 33.0 & 5.2 & 061 & 68 & 005 & 015 & 105 & SS \\
\hline CM19971108-10:03:03 & 086.96 & 35.33 & 16.4 & 7.5 & 079 & 69 & 002 & 034 & 124 & SS \\
\hline CM19971109-00:25:01 & 088.56 & 33.58 & 33.0 & 5.3 & 046 & 32 & -060 & 030 & 120 & $\mathrm{NF}$ \\
\hline CM20001126-02:01:54 & 089.71 & 36.23 & 29.5 & 5.3 & 298 & 38 & 014 & 080 & 170 & $\mathrm{UF}$ \\
\hline CM20010305-15:50:14 & 086.76 & 34.47 & 15.0 & 5.9 & 170 & 64 & -170 & 033 & 123 & SS \\
\hline CM20030707-06:55:54 & 089.59 & 34.67 & 33.0 & 5.8 & 060 & 81 & -006 & 015 & 105 & SS \\
\hline CM20040327-18:47:35 & 089.35 & 34.00 & 12.0 & 6.0 & 187 & 44 & -105 & 016 & 106 & $\mathrm{NF}$ \\
\hline CM20040327-20:05:57 & 089.19 & 33.87 & 18.4 & 5.0 & 044 & 36 & -049 & 021 & 111 & NF \\
\hline CM20040328-22:05:47 & 089.37 & 34.07 & 17.7 & 5.2 & 051 & 62 & -030 & 013 & 103 & SS \\
\hline CM20040328-22:27:31 & 089.28 & 33.91 & 16.9 & 5.1 & 046 & 50 & -039 & 015 & 105 & NF \\
\hline CM20040406-10:30:37 & 089.25 & 33.83 & 12.0 & 5.1 & 174 & 49 & -123 & 016 & 106 & NF \\
\hline CM20040422-10:02:22 & 089.33 & 33.88 & 17.7 & 5.2 & 036 & 49 & -050 & 010 & 100 & NF \\
\hline CM20040523-07:38:13 & 089.42 & 34.04 & 12.0 & 5.3 & 152 & 65 & -160 & 012 & 102 & SS \\
\hline CM20040703-14:10:50 & 089.41 & 34.09 & 13.6 & 5.2 & 055 & 65 & -024 & 016 & 106 & SS \\
\hline CM20060226-02:13:58 & 089.67 & 35.36 & 12.0 & 5.4 & 158 & 61 & -150 & 016 & 106 & NS \\
\hline CM20060301-09:36:47 & 089.67 & 35.40 & 18.6 & 5.1 & 060 & 50 & -031 & 026 & 116 & NS \\
\hline CM20060414-09:27:47 & 089.74 & 35.46 & 17.7 & 5.6 & 353 & 49 & -137 & 024 & 114 & NF \\
\hline CM20070315-18:30:09 & 089.49 & 35.50 & 18.6 & 5.0 & 041 & 46 & -051 & 018 & 108 & NF \\
\hline CM20070316-21:51:22 & 089.50 & 35.56 & 16.5 & 5.0 & 041 & 45 & -047 & 014 & 104 & NF \\
\hline CM20070505-17:38:21 & 090.03 & 34.67 & 24.5 & 5.0 & 347 & 74 & 179 & 032 & 122 & SS \\
\hline CM20080629-08:41:60 & 088.20 & 35.73 & 34.3 & 5.0 & 341 & 76 & 177 & 028 & 118 & SS \\
\hline CM20080629-12:47:31 & 088.44 & 35.76 & 18.1 & 5.5 & 259 & 82 & -004 & 035 & 125 & SS \\
\hline CM20080702-20:22:60 & 088.36 & 35.72 & 17.5 & 5.2 & 250 & 82 & -008 & 025 & 115 & SS \\
\hline Others & 25 & & & & & & & & & \\
\hline CM19790824-16:59:32 & 108.24 & 40.83 & 15.0 & 5.7 & 111 & 44 & -065 & 094 & 004 & $\mathrm{NF}$ \\
\hline CM19800712-20:39:42 & 094.08 & 37.03 & 15.0 & 5.2 & 161 & 09 & 106 & 060 & 150 & UF \\
\hline CM19801215-22:11:51 & 090.31 & 45.85 & 10.0 & 5.5 & 273 & 44 & 113 & 168 & 078 & $\mathrm{TF}$ \\
\hline CM19810209-23:13:15 & 086.98 & 36.53 & 10.0 & 5.3 & 222 & 30 & -053 & 005 & 095 & NF \\
\hline CM19821027-15:36:35 & 105.85 & 23.97 & 10.0 & 5.2 & 033 & 74 & 006 & 167 & 077 & SS \\
\hline CM19860424-00:22:17 & 089.54 & 47.33 & 33.0 & 5.0 & 345 & 70 & 161 & 034 & 124 & SS \\
\hline CM19870107-18:19:11 & 103.86 & 34.23 & 15.0 & 5.4 & 170 & 65 & 028 & 118 & 028 & SS \\
\hline
\end{tabular}


Table A1. (Continued.)

\begin{tabular}{|c|c|c|c|c|c|c|c|c|c|c|}
\hline \multirow[b]{2}{*}{ Data-time group event } & \multicolumn{3}{|c|}{ Location } & \multicolumn{4}{|c|}{ Focal mechanism data } & \multicolumn{2}{|c|}{$\mathrm{SH}$} & \multirow{2}{*}{$\begin{array}{l}\text { Stress } \\
\text { regime }\end{array}$} \\
\hline & Longitude & Latitude & $\overline{\text { Depth }}$ & $\overline{\mathrm{Mw}}$ & Strike & Dip & Slip & $\overline{\operatorname{Max}}$ & $\overline{\text { Min }}$ & \\
\hline CM19870810-12:12:20 & 105.63 & 37.57 & 21.3 & 5.3 & 336 & 25 & -075 & 148 & 058 & $\mathrm{NF}$ \\
\hline CM19871222-00:16:43 & 089.75 & 41.27 & 19.0 & 5.5 & 186 & 49 & 128 & 065 & 155 & $\mathrm{TF}$ \\
\hline CM19880103-21:32:31 & 106.86 & 38.13 & 15.0 & 5.2 & 110 & 57 & 005 & 064 & 154 & SS \\
\hline CM19880125-01:12:27 & 094.87 & 29.80 & 33.0 & 5.2 & 037 & 69 & 159 & 085 & 175 & SS \\
\hline CM19910819-06:05:43 & 085.41 & 46.03 & 54.8 & 5.2 & 068 & 36 & 051 & 000 & 090 & $\mathrm{TF}$ \\
\hline CM19941229-18:58:34 & 103.59 & 28.80 & 33.0 & 5.1 & 038 & 55 & 147 & 092 & 002 & $\mathrm{TS}$ \\
\hline CM19941231-02:57:20 & 109.43 & 20.56 & 32.1 & 5.3 & 008 & 68 & 017 & 140 & 050 & SS \\
\hline CM19950110-10:09:50 & 109.33 & 20.57 & 15.0 & 5.5 & 264 & 64 & -173 & 130 & 040 & SS \\
\hline CM19960503-03:32:50 & 109.69 & 40.72 & 25.0 & 6.0 & 308 & 75 & -012 & 084 & 174 & SS \\
\hline CM19970809-04:48:08 & 097.46 & 30.16 & 33.0 & 5.2 & 073 & 27 & -090 & 074 & 164 & NF \\
\hline CM19990130-03:51:10 & 088.70 & 41.67 & 23.3 & 5.4 & 116 & 36 & 099 & 022 & 112 & $\mathrm{TF}$ \\
\hline CM20000126-21:38:02 & 095.72 & 30.79 & 33.0 & 5.1 & 095 & 70 & 011 & 048 & 138 & SS \\
\hline CM20031113-02:35:15 & 104.10 & 34.61 & 15.0 & 5.1 & 347 & 42 & 053 & 109 & 019 & $\mathrm{TF}$ \\
\hline CM20031114-18:49:46 & 103.21 & 27.68 & 15.0 & 5.6 & 250 & 36 & -170 & 119 & 029 & UF \\
\hline CM20040810-10:26:18 & 103.78 & 27.16 & 15.1 & 5.3 & 156 & 85 & 001 & 111 & 021 & SS \\
\hline CM20050824-22:32:48 & 079.66 & 39.88 & 46.4 & 5.0 & 048 & 56 & 024 & 176 & 086 & $\mathrm{UF}$ \\
\hline CM20060825-05:51:47 & 104.31 & 28.00 & 17.4 & 5.0 & 355 & 50 & 045 & 114 & 024 & $\mathrm{TF}$ \\
\hline CM20070225-01:49:42 & 090.63 & 33.10 & 20.5 & 5.4 & 066 & 67 & -019 & 025 & 115 & SS \\
\hline
\end{tabular}

Note: Date-time group: CM (China Mainland) followed by date (year-month-day), time (hour-minute-second); Depth (estimated depth in km); Focal mechanism data: Mw (moment magnitude); Strike, Dip and Slip of focal plane; Horizontal stress orientations: $\mathrm{SH}, \max -\mathrm{S}_{\mathrm{Hmax}}, \min -\mathrm{S}_{\mathrm{hmin}}$.

\section{References}

Angelier J 1984 Tectonic analysis of fault slip data sets; J. Geophys. Res. 89 5835-5848.

Angelier J 1989 From orientation to magnitudes in palaeostress determinations using fault slip data; J. Struct. Geol. 11 37-50.

Audemard F A, Romero G, Rendon H and Cano V 2005 Quaternary fault kinematics and stress tensors along the southern Caribbean from fault-slip data and focal mechanism solutions; Earth Sci. Rev. 69 181-233.

Barth A, Wenzel F and Giardini D 2007 Frequency sensitive moment tensor inversion for light to moderate magnitude earthquakes in eastern Africa; Geophys. Res. Lett. 34(L15302) 1-5.

Baruah S, Baruah S and Kayal J R 2013 State of tectonic stress in northeast India and adjoining South Asia Region: An appraisal; Bull. Seismol. Soc. Am. 103(2A) 894-910.

Baruah S, Baruah S, Saikia S, Shrivastava M N, Sharma A, Reddy C D and Kayal J R 2016 State of tectonic stress in Shillong Plateau of northeast India; Phys. Chem. Earth $9536-49$.

Bott M H P 1959 The mechanism of oblique slip faulting; Geol. Mag. 96 109-117.

Cortes M and Angelier J 2005 Current states of stress in the northern Andes as indicated by focal mechanisms of earthquakes; Tectonophys. 403 29-58.

Delvaux D and Sperner B 2003 Stress tensor inversion from fault kinematic indicators and focal mechanism data: The TENSOR program. In: New insights into structural interpretation and modeling (ed.) Nieuwland D, J. Geol. Soc. London, pp. 75-100.

Delvaux D and Barth A 2010 African stress pattern from formal inversion of focal mechanism data; Tectonophys. $482105-128$.
Delvaux D, Moeys R, Stapel G, Melnikov A and Ermikov V 1995 Palaeostress reconstructions and geodynamics of the Baikal region, Central Asia, Part 1: Palaeozoic and Mesozoic pre-rift evolution; Tectonophys. 252 61-101.

Delvaux D, Moeys R, Stapel G, Petit C, Levi K, Miroshnichenko A, Ruzhich V and Sankov V 1997 Palaeostress reconstructions and geodynamics of the Baikal region, Central Asia, Part 2: Cenozoic rifting; Tectonophys. 282 1-38.

Deng Q D, Zhang Y M, Xu G L and Fan F T 1979 On the tectonic stress field in China and its relation to plate movement; Seismol. Geol. 1(1) 11-22 (in Chinese with English abstract).

Dziewonski A M, Ekstrom G, Franzen J E and Woodhouse J H 1987 Global seismicity of 1977: Centroid-moment tensor solutions for 471 earthquakes; Phys. Earth Planet. Int. 45 11-36.

Etchecopar A, Vasseur G and Daigniers M 1981 An inverse problem in microtectonics for the determination of stress tensors from fault striation analysis; J. Struct. Geol. 3 51-65.

Gao M T 2003 New national seismic zoning map of China; Acta Seismol. Sin. 25(6) 630-636 (in Chinese with English abstract).

Gephart J W and Forsyth D W 1984 An improved method for determining the regional stress tensor using earthquake focal mechanism data: Application to the San Fernando earthquake sequence; J. Geophys. Res. 89(B11) 9305-9320.

Giardini D 1999 The global seismic hazard assessment program (GSHAP) 1992/1999; Ann. Geofis. 42(6) 957-974.

Heidbach O, Tingay M, Barth A, Reinecker J, Kurfeß D and Muller B 2010 Global crustal stress pattern based on the World Stress Map database release 2008; Tectonophys. 482 3-15. 
Holt W E, Chamot-Rooke N, Le Pichon X, Haines A J, Shen-Tu B and Ren J 2000 The velocity field in Asia inferred from Quaternary fault slip rates and GPS observations; J. Geophys. Res. 105(B8) 19185-19210.

Hou G T, Wang C C, Li J H and Qian X L 2006 Late paleoproterozoic extension and a palaeostress field reconstruction of North China Craton; Tectonophys. 422 89-98.

$\mathrm{Ju}$ W, Hou G T and Hari K R 2013a Mechanics of mafic dyke swarms in the Deccan Large Igneous Province: Palaeostress field modeling; J. Geodyn. 66 79-91.

Ju W, Hou G T, Huang S Y and Ren K X 2013b Structural fracture distribution and prediction of the Lower Jurassic Ahe Formation Sandstone in the Yinan-Tuzi area, Kuqa Depression; Geotect. Metal. 37(4) 592-602 (in Chinese with English abstract).

Ju W, Hou G T and Zhang B 2014 Insights into the damage zones in fault-bend folds from geomechanical models and field data; Tectonophys. 610 182-194.

Ju W and Sun W F 2016 Tectonic fractures in the Lower Cretaceous Xiagou Formation of Qingxi Oilfield, Jiuxi Basin, NW China. Part one: Characteristics and controlling factors; J. Petrol. Sci. Eng. 146 617-625.

Ju W, Sun W F and Hou G T 2015 Insights into the tectonic fractures in the Yanchang Formation interbedded sandstone-mudstone of the Ordos Basin based on core data and geomechanical models; Acta Geol. Sin-Engl. 89(6) 1986-1997.

Ju W, Sun W F, Ma X J and Jiang H 2016 Tectonic stress accumulation in Bohai-Zhangjiakou Seismotectonic Zone based on 3D visco-elastic modelling; J. Earth. Syst. Sci. 125(5) 1021-1031.

Lund B and Townend J 2007 Calculating horizontal stress orientations with full or partial knowledge of the tectonic stress tensor; Geophys. J. Int. 270 1328-1335.

Lunina O V and Gladkov A S 2007 Late Cenozoic fault pattern and stress fields in Barguzin rift (Baikal region); Russ. Geol. Geophys. 48 598-609.

Naimi-Ghassabian N, Khatib M, Nazari H and Heyhat M 2015 Present-day tectonic regime and stress patterns from the formal inversion of focal mechanism data, in the North of Central-East Iran Blocks; J. African. Earth Sci. 111 113-126.

Sperner B, Muller B, Heidbach O, Delvaux D, Reinecker J and Fuchs K 2003 Tectonic stress in the Earth's crust: Advances in the World Stress Map Project, In: New insights into structural interpretation and modeling (ed.) Nieuwland D A; J. Geol. Soc. London, pp. 101-116.

Tapponnier P and Molnar P 1977 Active faulting and tectonics in China; J. Geophys. Res. 82(20) 2905-2930.

Tapponnier P, Peltzer G and Armijo R 1986 On the mechanics of the collision between India and Asia; In: Collision tectonics (eds) Ramsay J G, Coward M P and Ries A, J. Geol. Soc. London, pp. 115-157.

Tapponnier P, Peltzer G, Le Dain A Y, Armijo R and Cobbold P 1982 Propagating extrusion tectonics in Asia: New insights from simple experiments with plasticine; Geology 10 611-616.
Wang S Y, Xu Z H, Yu Y X and Zhang L 1996 Inversion for the plate driving forces acting at the boundaries of China and its surroundings; Acta Geophys. Sin. 39(6) 764-771 (in Chinese with English abstract).

Wang Q, Zhang P Z, Freymueller J T, Bilham R, Larson K M, Lai X A, You X Z, Niu Z J, Wu J C, Li Y X, Liu J N, Yang Z Q and Chen Q Z 2001 Present-day crustal deformation in China constrained by global positioning system measurements; Science 294 574-577.

Xie F R and Liu G X 1989 Analysis of Neotectonic stress field in area of the central segment of Altun fault zone, China; Earthq. Res. China 5(3) 26-36 (in Chinese with English abstract).

Xie F R, Zhang S M, Dou S Q, Cui X F and Shu S B 1999 Evolution characteristics of Quaternary tectonic stress field in the north and east margin of Qinghai-Xizang plateau; Acta Seismol. Sin. 12(5) 550-561 (in Chinese with English abstract).

Xie F R, Cui X F, Zhao J T, Chen Q C and Li H 2004 Regional division of the recent tectonic stress field in China and adjacent areas; Acta Geophys. Sin. 47(4) 654-662 (in Chinese with English abstract).

$\mathrm{Xu} \mathrm{J} \mathrm{R} \mathrm{and} \mathrm{Zhao} \mathrm{Z} \mathrm{X} 2006$ Regional characteristics of the lithospheric stress field and tectonic motions in China and its adjacent areas; Geol. China 33(4) 782-792 (in Chinese with English abstract).

Yao D Y, Du Y C and Liu S Y 1991 The focal mechanisms in north China; North. China. Earthq. Sci. 9(3) 37-48 (in Chinese with English abstract).

Yin A 2010 Cenozoic tectonic evolution of Asia: A preliminary synthesis; Tectonophys. 488 293-325.

Yin A and Nie S Y 1993 An indentation model for North and South China collision and the development of the Tan-Lu and Honam fault systems, eastern Asia; Tectonics 12(4) 801-813.

Zhang P Z 1993 Seismic hazard assessment in Continental Asia; Ann. Geofis. XXXVI(3-4) 41-59.

Zhang P Z, Yang Z X, Gupta H K, Bhatia S C and Shedlock K M 1999 Global seismic hazard assessment program (GSHAP) in continental Asia; Ann. Geofis. 42(6) 11671190.

Zhang Y Q 1999 Kinematic history and changes in tectonic stress regime during the Cenozoic along the Qinling and southern Tanlu Fault Zones; Acta Geol. Sin. 73(3) $264-274$

Zhang Y Q, Ma Y S, Yang N, Shi W and Dong S 2003 Cenozoic extensional stress evolution in North China; J. Geodyn. 36 591-613.

Zhang Z P and Wang Q C 2004 The summary and comment on fault-slip analysis and palaeostress reconstruction; Adv. Earth Sci. 19(4) 605-613 (in Chinese with English abstract).

Zhao B 2015 GPS velocity field of CMONOC with respect to Eurasia; ftp://ftp.cgps.ac.cn/products/velocity/image/ cmnc_vel_eura_grd_flt.png.

Zoback M L 1992 First- and second-order patterns of stress in the lithosphere: The world stress map project; J. Geophys. Res. 97(B8) 11703-11728. 